\title{
Testosterone and glucose metabolism in men: current concepts and controversies
}

\author{
Mathis Grossmann ${ }^{1,2}$ \\ ${ }^{1}$ Department of Medicine Austin Health, University of Melbourne, 145 Studley Road, Heidelberg, \\ Victoria 3084, Australia \\ ${ }^{2}$ Department of Endocrinology, Austin Health, Heidelberg, Victoria, Australia
}

Correspondence should be addressed to M Grossmann

Email

mathisg@unimelb.edu.au

\begin{abstract}
A wealth of observational studies show that low testosterone is associated with insulin resistance and with an increased risk of diabetes and the metabolic syndrome. Experimental studies have identified potential mechanisms by which low testosterone may lead to insulin resistance. Visceral adipose tissue is an important intermediate in this relationship. Actions of testosterone or its metabolite oestradiol on other tissues such as muscle, liver, bone or the brain, and body composition-independent effects may also play a role. However, definitive evidence from randomised controlled trials (RCTs) to clarify whether the association of low testosterone with disordered glucose metabolism is causative is currently lacking. It therefore remains possible that this association is due to reverse causation, or simply originates by association with common health and lifestyle factors. RCTs of testosterone therapy in men with or without diabetes consistently show modest metabolically favourable changes in body composition. Despite this, testosterone effects on glucose metabolism have been inconsistent. Recent evidence suggests that the hypothalamic-pituitary-testicular axis suppression in the majority of obese men with metabolic disorders is functional, and may be, at least in part, reversible with weight loss. Until further evidence is available, lifestyle measures with emphasis on weight reduction, treatment of comorbidities and optimisation of diabetic control should remain the first-line treatment in these men. Such measures, if successful, may be sufficient to normalise testosterone levels in men with metabolic disorders, who typically have only modest reductions in circulating testosterone levels.
\end{abstract}
Key Words
- testosterone
- diabetes
- glucose metabolism
- insulin resistance
- obesity

\section{Introduction: significance of the clinical problem}

Around 50\% of ageing, obese men presenting to the diabetes clinic have lowered testosterone levels relative to reference ranges based on healthy young men (Grossmann 2011). Many have symptoms consistent with androgen deficiency, but such symptoms are non-specific and overlap with comorbidities. Therefore, the clinician is commonly faced with the question as to whether testosterone therapy should be considered. There is vigorous debate about this issue. Only a small proportion of these men will have classical hypogonadism due to recognisable hypothalamic-pituitary-testicular (HPT) axis pathology, an important diagnosis not to be missed. In contrast, the risk-benefit ratio of testosterone therapy for the large proportion of men with metabolic disorders, 
defined here as type 2 diabetes and or the metabolic syndrome, but without clear-cut classical hypogonadism, is not known. This is because we have insufficient evidence to conclusively answer three key questions: first, is low testosterone is a causal factor or a biomarker for metabolic disorders and associated clinical features? Second, even if low testosterone is pathogenic, we do not know whether testosterone treatment meaningfully improves patientimportant health outcomes. Third, even if testosterone treatment improves outcomes, we do not know whether we should we use this treatment, because this depends on additional factors, such as long-term risks, cost and inconvenience of treatment, and comparisons to established therapies. The absence of high-level evidence in this area is illustrated by the Endocrine Society testosterone therapy in men with androgen deficiency clinical practice guidelines (Bhasin et al. 2010), which are appropriate for, but not specific to men with metabolic disorders. All 32 recommendations made in these guidelines are based on either very low or low quality evidence. Compared to other Endocrine Society guidelines, they have the thirdlowest evidence backing: only the guidelines on hirsutism and on androgen therapy in women have less (Hazlehurst et al. 2013). Appropriately therefore, the Endocrine Society concludes that 'the information about the benefits and risks of testosterone therapy in men with type 2 diabetes is either limited or not available' (Bhasin et al. 2010). Similarly, the International Society of Andrology states that it is 'premature to recommend testosterone therapy for the metabolic syndrome or diabetes' (Wang et al. 2009).

A key concept relates to making a distinction between replacement and pharmacological testosterone therapy, although indications may overlap (Fig. 1; McLachlan 2010, Grossmann 2011, Spitzer et al. 2013). On the one hand, in organic androgen deficiency due to intrinsic damage of the gonadal axis, pathological androgen deficiency is treated by normalising circulating testosterone levels. Here, the risk-benefit ratio of treatment is expected to be favourable based on open label studies and almost 70 years of clinical experience. On the other hand, in functional androgen deficiency due to axis suppression because of age-related comorbidities, treatment may aim for a specific health outcome, such as improvement of glucose metabolism, and symptomatic response is a less certain benefit. In this setting, randomised control trial evidence for efficacy and safety is required (Fig. 1). However, it should be noted that, in certain scenarios such as opioid-induced hypogonadism where narcotic analgesia cannot be stopped, functional

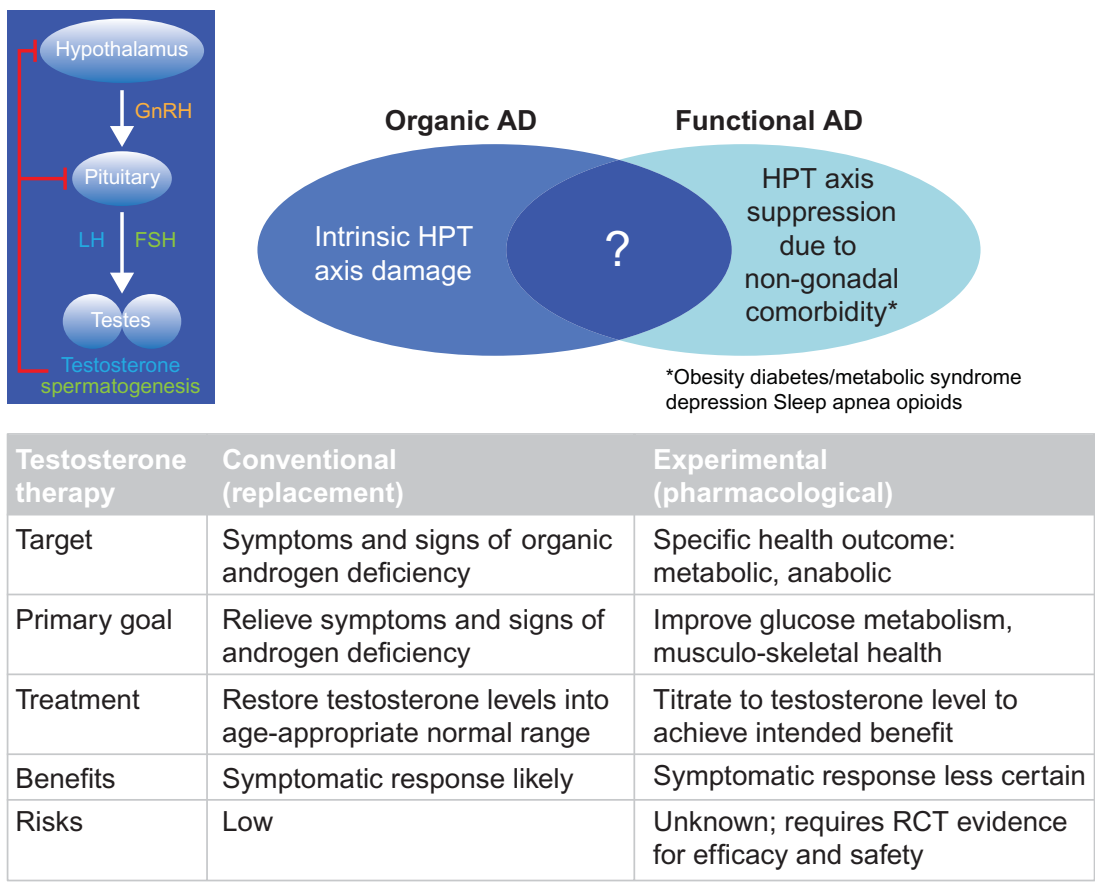

\section{Figure 1}

Organic vs functional androgen deficiency. A conceptual framework to distinguish approach to organic and functional androgen deficiency. Both conditions may overlap. It should be noted that even functional androgen deficiency may be associated with profound hypogonadism that requires testosterone replacement therapy. One example is patients with painful diabetic neuropathy requiring narcotic analgesia. If opioids cannot be stopped, hypogonadism may respond well to testosterone replacement. HPT, hypothalamic-pituitary-testicular; $A D$, androgen deficiency. 
androgen deficiency may require, and respond well to, testosterone replacement.

In this review, I will discuss current concepts and controversies in the relationship between testosterone and metabolic status. I will highlight challenges in the assessment and management of androgen deficiency in men with metabolic disorders, and review observational, mechanistic and therapy studies of testosterone in men with type 2 diabetes and the metabolic syndrome. The material discussed is based on peer-reviewed journals indexes identified by searching the PubMed database from 1970 to September 2013, using the terms 'diabetes', 'metabolic syndrome', 'testosterone', 'androgen', 'insulin resistance and males'. Given several recent reviews in this area (Dandona \& Dhindsa 2011, Grossmann 2011, Allan 2013, Rao et al. 2013), particular emphasis is given to more recent studies. Articles published before 2012 are highlighted only if they provide essential background data for the more recent studies.

\section{Androgen deficiency in men with metabolic disorders}

According to the Endocrine Society, androgen deficiency is a clinical syndrome, diagnosed by the presence of both 'consistent symptoms and signs and unequivocally low serum testosterone levels' (Bhasin et al. 2010). Hypogonadism refers to intrinsic pathology of the HPT axis and includes both androgen deficiency and spermatogenic failure. Hypotestosteronaemia denotes biochemical hypoandrogenism, defined as lowered circulating testosterone levels according to an arbitrary cut-off, without reference to symptoms and signs. Although the diagnosis of androgen deficiency is relatively straightforward to make in otherwise healthy younger men, it is more difficult in ageing men with comorbidities.

\section{Symptoms of androgen deficiency}

Symptoms of androgen deficiency are non-specific. In ageing obese men with metabolic disorders, they are confounded by comorbidities. Therefore, the presence of symptoms is less specific for the diagnosis of androgen deficiency, compared with otherwise healthy young men with organic androgen deficiency, in whom such confounders are absent. In the European Male Ageing Study (EMAS) of community dwelling men, androgen deficiency was diagnosed according to strict criteria. Despite this, the prevalence of even the most specific sexual symptoms was relatively high in men with normal testosterone levels (Wu et al. 2010). In a cross-sectional study of 350 ageing men with diabetes, $55-70 \%$ of men with a clearly low testosterone had symptoms compatible with androgen deficiency. However, even $50-55 \%$ of men with clearly normal testosterone also had such symptoms. The presence of symptoms was more closely linked to increasing age than to testosterone levels (Kapoor et al. 2007). Similarly, in a more recent study, the inverse association of testosterone levels with symptoms of whether androgen deficiency, erectile dysfunction or quality of life has been found to be weak. The association was not significant if adjusted for age, which again was the best predictor (Biswas et al. 2012).

\section{Testosterone levels}

In cohort studies from the Framingham Heart study, EMAS, Osteoporotic Fractures in Men study (Bhasin et al. 2011b) and the Western Australian Health in Men study (Yeap et al. 2012a), men with diabetes were consistently about twice as likely to have lower testosterone levels (determined by liquid chromatography/mass spectrometry (LCMS/MS)) compared with men without diabetes. Cross-sectional studies uniformly show that 30-50\% of men with type 2 diabetes have lowered circulating testosterone levels, relative to references based on healthy young men (Dhindsa et al. 2004, Kapoor et al. 2007, Grossmann et al. 2008). However, the extent of hypotestosteronaemia is modest: in meta-analyses of case-control studies, mean unadjusted pooled differences in total testosterone relative to men without diabetes ranged from $-2.66 \mathrm{nmol} / 1$ (95\% CI -3.45 to -1.86$)$ (Ding et al. 2006) to $-2.99 \mathrm{nmol} / 1$ ( $95 \% \mathrm{CI}-3.59$ to -2.40$)$ (Corona et al. 2010). This association of low testosterone with type 2 diabetes persists even if adjusted for multiple confounders including age and obesity. However, the adjusted difference between men with and without diabetes becomes less: $-1.61 \mathrm{nmol} / 1$ (95\% CI -2.56 to -0.65 ) (Ding et al. 2006). In a more recent cross-sectional study of 1849 obese men, the presence of diabetes was associated with a significant $(P<0.05)$ but marginal reductions in total testosterone $(-0.8 \mathrm{nmol} / \mathrm{l})$ and free testosterone ( $-13 \mathrm{pmol} / \mathrm{l}$ ) levels (Dhindsa et al. 2010). Indeed, low testosterone is more predictive of the metabolic syndrome in lean men. This suggests that obesity is a dominant risk factor that can override the contribution of the lowered androgen status (Kupelian et al. 2006).

Findings similar to type 2 diabetes were reported for men with the metabolic syndrome, which were associated with reductions in total testosterone of $-2.2 \mathrm{nmol} / \mathrm{l}(95 \%$ $\mathrm{CI}-2.41$ to 1.94 ) and in free testosterone of $-0.26 \mathrm{pmol} / 1$

Published by Bioscientifica Ltd 
(95\% CI 0.39 to 0.13) (Corona et al. 2011). Thus, both diabetes and the metabolic syndrome are associated with a modest reduction in testosterone, in magnitude comparable with the effect of 10 years of ageing. More marked reductions in testosterone levels are relatively uncommon even in men with diabetes: in a cross-sectional study of 580 men presenting to a tertiary diabetes referral centre, $19 \%$ had a total testosterone of $<8.0 \mathrm{nmol} / \mathrm{l}$ and $5 \%$ of $<5.0 \mathrm{nmol} / 1$ (Grossmann et al. 2008). Therefore, marked reductions in circulating testosterone require a thorough clinical evaluation. They should not be dismissed to be a non-specific consequence of diabetes.

As in the general male population, the prevalence of hypotestosteronaemia in men with metabolic disorders increases with age and obesity (Grossmann et al. 2008). In a recent cross-sectional study of 240 middle-aged men (mean age 54 years) with either type 2 diabetes, type 1 diabetes or without diabetes (Ng Tang Fui et al. 2013b), increasing BMI and age were dominant drivers of low total and free testosterone respectively. This was independent of the presence or absence of diabetes. Prevalence of hypotestosteronaemia (total testosterone $<8 \mathrm{nmol} / \mathrm{l}$ ) in these middle-aged men was low, occurring in $0,6.2$ and $2.5 \%$ of men with type 1 , type 2 and without diabetes respectively (Ng Tang Fui et al. 2013b).

\section{End organ deficits of androgen deficiency}

The diagnosis of androgen deficiency in ageing men with comorbidities is difficult. Therefore, there has been increasing interest in identifying objective evidence of androgen deficiency. This has been attempted either by using biomarkers of androgen action or by documenting deficits in androgen-responsive organs. In a cross-sectional survey of 2966 men participating in the EMAS cohort which included $8 \%$ of men with type 2 diabetes, the prevalence of late onset hypogonadism (LOH) diagnosed by the presence of three sexual symptoms and a total testosterone of $<11 \mathrm{nmol} / 1$ or a free testosterone $<230 \mathrm{pmol} / \mathrm{l}$ was $2.1 \%$ (Wu et al. 2010). Men with $\mathrm{LOH}$ had significantly lower bone density, haemoglobin and lean body mass compared with men who did not meet the diagnostic criteria for LOH (Tajar et al. 2012). More recently, prostate-specific antigen (PSA) has been proposed as a tissue marker of testosterone deficiency: in a large cohort of $>3000$ men, a PSA of $<0.65 \mu \mathrm{g} / 1$ predicted a total testosterone of $<8 \mathrm{nmol} / \mathrm{l}$ with modest sensitivity (65\%) and specificity (56\%). A low PSA was associated with delayed puberty, lower testicular volume and interestingly, with the presence of the metabolic syndrome (hazard ratio $1.5(1.2-1.8), P<0.001)$ and type 2 diabetes (hazard ratio 2.0 (1.7-2.5), $P<0.001$ ) (Rastrelli et al. 2013). In a cohort of 138 men with type 2 diabetes, free testosterone levels were inversely associated with bone density at some but not all sites (Dhindsa et al. 2007). In a cross-sectional study of 490 men with type 2 diabetes, there was a strong independent association of low testosterone with anaemia (Grossmann et al. 2009). Collectively, these reports suggest that low testosterone is not merely a marker of insulin resistance or obesity, but may be associated with biological consequences of androgen deficiency at the tissue level. However, their cross-sectional design limits inferences about causality. In addition, the aetiology of sarcopaenia, low bone mass and anaemia is multifactorial. It is therefore not known whether such deficits in androgen-dependent organs are causally related to hypotestosteronaemia. Alternatively, a high burden of comorbidities may be responsible for both the lowered testosterone level and these somatic deficits.

In summary, the diagnosis of androgen deficiency in men with metabolic disorders remains challenging. This is due to high prevalence of non-specific symptoms and of modest reductions in testosterone. This may, at least in part, be a non-specific consequence of chronic disease. Stringent diagnostic criteria (Wu et al. 2010) or organic markers of androgen deficiency may be helpful to limit over-diagnosis of androgen deficiency in such men. Still, better biomarkers are desirable. Unfortunately, no gold standard for the diagnosis exists. Importantly, such diagnostic criteria do not inform about the risk-benefit ratio of testosterone therapy. Rather they should be helpful in selecting men suited to participate in randomised controlled trials (RCTs) of testosterone therapy.

\section{Low testosterone in men with metabolic disorders: cause or consequence?}

In men, low testosterone is a marker of poor health, and may improve our ability to predict risk. For example, in a recent prospective cohort study of men presenting for liver transplantation, low testosterone predicted mortality independently of the model of end-stage liver disease score, the standard score used to prioritise the allocation of liver transplants (Grossmann et al. 2012). It is evident from multiple studies that low testosterone identifies men with an adverse metabolic phenotype (Grossmann et al. 2010). Diabetic men with low testosterone are significantly more likely to be obese or insulin resistant. Even if aggressively managed to evidence-based targets, they are still more likely to have an adverse lipid profile (Fig. 2). They also

Published by Bioscientifica Ltd. 

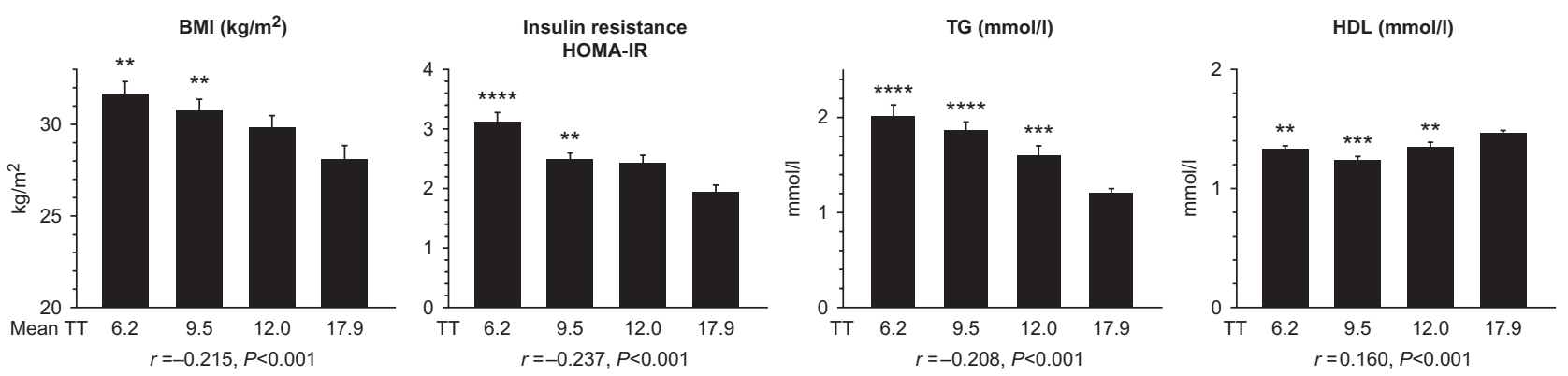

Figure 2

Low testosterone is associated with an adverse metabolic phenotype. Data were analysed using simple (Pearson) calculation and multiple regression. HOMAIR, homeostasis model assessment of insulin resistance; Tg, triglycerides (data from Grossmann et al. 2008).

have increased inflammation, evidenced by higher CRP levels (Grossmann et al. 2008). Low total testosterone has recently been associated with increased mortality in an observational study of men with diabetes (Muraleedharan et al. 2013). Significance, however, was lost when age and sex hormone-binding globulin (SHBG) were taken into account. Bioavailable but not free testosterone was independently predictive of mortality (Muraleedharan et al. 2013). These findings may suggest that the increased mortality is driven by imperfect adjustment of confounders. This is consistent with a recent meta-analysis which attributed the increased mortality in men with lowered testosterone to differences in underlying health status between cohorts (Araujo et al. 2011). Ultimately, observational studies cannot answer the question to what extent low testosterone causally contributes to alterations in glucose metabolism. It remains possible that low testosterone is a consequence of insulin resistance, or simply a biomarker, co-existing because of in-common risk factors.

In prospective studies, reviewed in detail elsewhere (Grossmann et al. 2010) the inverse association of low testosterone with metabolic syndrome or diabetes is less consistent for free testosterone compared with total testosterone. This is because of the confounding effects of SHBG, itself being a strong associate of insulin resistance (Wallace et al. 2013). In a study from the Framingham cohort, SHBG but not testosterone was prospectively and independently associated with incident metabolic syndrome (Bhasin et al. 2011a). Mendelian randomisation studies, which are less likely to be confounded than traditional observational studies, have associated low SHBG (Ding et al. 2009) but not testosterone (Haring et al. 2013) with an increased risk of future diabetes. In cross-sectional studies of men with (Grossmann et al. 2008) and without (Bonnet et al. 2013) diabetes, SHBG but not testosterone was inversely associated with worse glycaemic control. SHBG may have biological actions beyond serving as a carrier protein for and regulator of circulating sex steroids (Wallace et al. 2013). However, this is yet unproven. An interventional study designed to test the effects of altering SHBG levels on glycaemic outcomes will be necessary to confirm causality. However, no intervention readily exists that can modulate SHBG concentrations independent of confounders.

In men with diabetes, free testosterone, if measured by gold standard equilibrium dialysis (Dhindsa et al. 2004), is reduced. Low free testosterone remains inversely associated with insulin resistance, independent of SHBG (Grossmann et al. 2008). This suggests that the low testosterone-dysglycaemia association is not solely a consequence of low SHBG.

While the association of low testosterone with metabolic disorders is weakened by adjustment for crude measures of adiposity, it becomes non-significant in studies that carefully adjusted for the amount of visceral adipose tissue volume (Grossmann 2011). Experimental evidence reviewed below suggests that visceral adipose tissue is an important intermediate (rather than a confounder) in the inverse association of testosterone with insulin resistance and metabolic disorders.

\section{Evidence that low testosterone leads to increased insulin resistance}

Experimental evidence, summarised in Fig. 3, suggests proposed mechanisms by which testosterone decreases insulin resistance: testosterone promotes the commitment of pluripotent stem cells into the myogenic lineage and inhibits their differentiation into adipocytes (Singh et al. 2003). This provides a molecular explanation for the

Published by Bioscientifica Ltd 


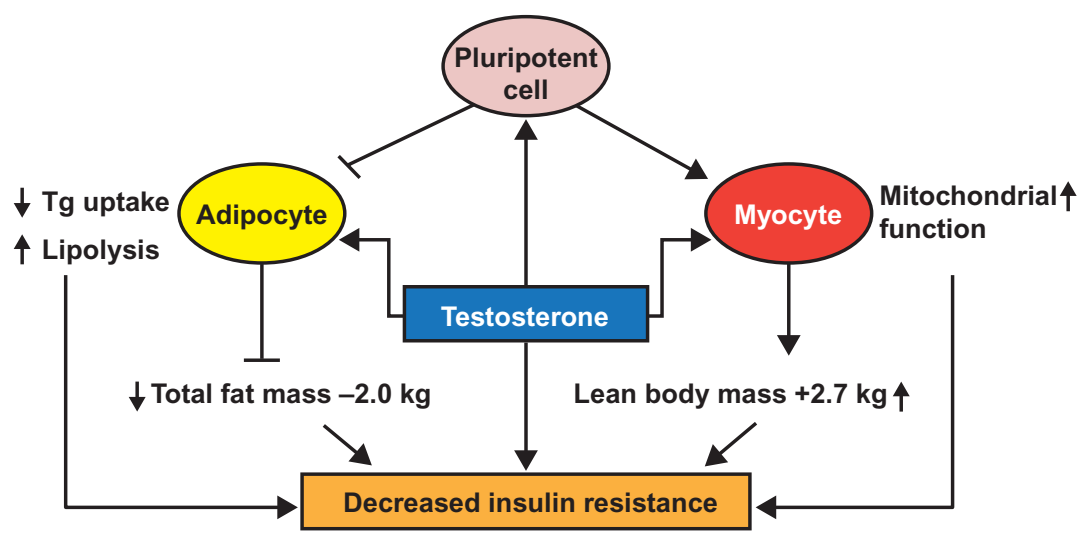

Figure 3

Mechanisms by which testosterone may decrease insulin resistance. Mechanisms may include testosterone actions on pluripotent stem cells and differentiated cell function. Data support both body composition-

modest reductions in fat mass $(-2 \mathrm{~kg})$ and increases in lean body mass $(+2-3 \mathrm{~kg}$ ) reported in RCTs of testosterone therapy (Isidori et al. 2005, Bhasin et al. 2006). These changes are expected to be metabolically favourable. In addition, testosterone regulates the metabolic functions of mature adipocytes (Xu et al. 1991, Marin et al. 1995) and myocytes (Pitteloud et al. 2005) in ways that reduce insulin resistance. Pre-clinical evidence (reviewed in Rao et al. (2013)) suggests that at the cellular level, testosterone may improve glucose metabolism by modulating the expression of the glucose-transported Glut 4 and the insulin receptor, as well as by regulating key enzymes involved in glycolysis. More recently testosterone has been shown to protect murine pancreatic $\beta$ cells against glucotoxicity-induced apoptosis (Hanchang et al. 2013).

Most studies suggest that the effects of testosterone on insulin resistance occur via changes in body composition. There is also evidence that testosterone regulates insulin sensitivity directly and acutely (Yialamas et al. 2007). Interestingly, a reciprocal feedback also appears to exist, given that not only chronic (Cameron et al. 1990, Allan 2013) but also, as shown more recently (Iranmanesh et al. 2012, Caronia et al. 2013), acute hyperglycaemia can lower testosterone levels.

In men with prostate cancer commencing androgen deprivation therapy, both total as well as, although not in all studies (Smith 2004), visceral fat mass increases (Hamilton et al. 2011) within 3 months. This is associated with increased insulin resistance, which is further aggravated by concurrent loss of muscle mass (Grossmann \& Zajac 2011b). More prolonged (>12 months) androgen deprivation therapy has been associated with increased risk dependent as well as body composition-independent testosterone actions. For references, see text.

of diabetes in several large observational registry studies. The estimated number to harm to cause one incident CASE of diabetes is $\sim 100$ (Grossmann \& Zajac 2011b). Acute sex steroid withdrawal also induced insulin resistance in healthy men (Yialamas et al. 2007). In addition, men with Klinefelter syndrome have an increased risk of metabolic disorders. Interestingly, greater body fat mass is already present before puberty. This indicates that chromosomal factors may also play a role (Groth et al. 2013).

Whether testosterone promotes insulin sensitivity via effects on energy expenditure and/or physical activity is less well studied. In rodent models, there is evidence that testosterone may increase the metabolic rate via androgen receptor-dependent actions on skeletal muscle (Fernando et al. 2010). Mice lacking the androgen receptor have decreased physical activity, which may, at least in part, be responsible for their sarcopaenic obesity (Rana et al. 2011). Data from human studies are less clear, as RCTs of testosterone therapy have, to date, not measured changes in physical activity carefully. A small study investigating the effects of acute biochemical castration in ten healthy younger men (mean age 41 years) did not find any changes in energy expenditure after 4 weeks of castration (Rabiee et al. 2010). A larger acute chemical castration study in 54 men aged 50-80 years similarly did not find any change in respiratory exchange ratio or resting energy expenditure after 3 weeks of testosterone suppression (Santosa et al. 2010). The authors concluded that, because abrupt changes in sex steroids do not change resting substrate oxidation, changes that can be observed after more prolonged periods of deficiency are most likely due to direct effects of sex steroids on body composition.

Published by Bioscientifica Ltd. 
Testosterone has also been shown to reduce the concentration of pro-inflammatory cytokines in some, but not all studies, reviewed recently in Kelly \& Jones (2013). It is not know whether this effect is independent of testosterone-induced changes in body composition.

Collectively, the observations discussed in this section suggest that it is the decrease in testosterone that causes insulin resistance and diabetes. One important caveat remains: the strongest evidence that low testosterone is the cause rather than consequence of insulin resistance comes from men with prostate cancer (Grossmann \& Zajac 2011a) or biochemical castration, and from mice lacking the androgen receptor. How findings with such extreme manipulations of sex steroids (Yialamas et al. 2007, Hamilton et al. 2011, Rana et al. 2011) apply to the majority of men with diabetes who only have modest reductions in testosterone is therefore not known.

\section{Evidence that low testosterone is a consequence of dysglycaemia and associated clinical factors}

There is also evidence for reverse causality, demonstrating that low testosterone may be a consequence of disordered glucose metabolism and obesity. In prospective studies, the metabolic syndrome predicts low testosterone (Laaksonen et al. 2005). Several large prospective studies have shown that weight gain or development of type 2 diabetes is major drivers of the age-related decline in testosterone levels (Travison et al. 2007, Haring et al. 2010). Indeed, there is increasing evidence that healthy ageing by itself is generally not associated with marked reductions in testosterone (Sartorius et al. 2012). Circulating testosterone, on an average 30\%, is lower in obese compared with lean men, which is more than the purely age-dependent decrease between 40 and 80 years of age (Tajar et al. 2010).

\section{Testosterone and insulin resistance: a bilateral relationship}

The current evidence is therefore consistent with a bi-directional relationship between visceral fat and testosterone, which may initiate a self-perpetuating cycle promoting insulin resistance (Fig. 4). In addition, interactions of testosterone with other organ systems such as muscle (Pitteloud et al. 2005) bone (Lee et al. 2007, Oury et al. 2011), liver (Lin et al. 2008) and the CNS (Yu et al. 2013) may also modulate insulin resistance. However, until causality is confirmed by adequately designed intervention trials, it remains possible that this relationship is not pathogenic but an epiphenomenon of shared risk factors. According to this bi-directional model, increased visceral fat not only promotes insulin resistance but also elaborates a variety of circulating mediators that inhibit the HPT axis at multiple levels. Only 5\% of men with type 2 diabetes have elevated LH levels (Dhindsa et al. $2004,2011)$. This is consistent with recent findings that the

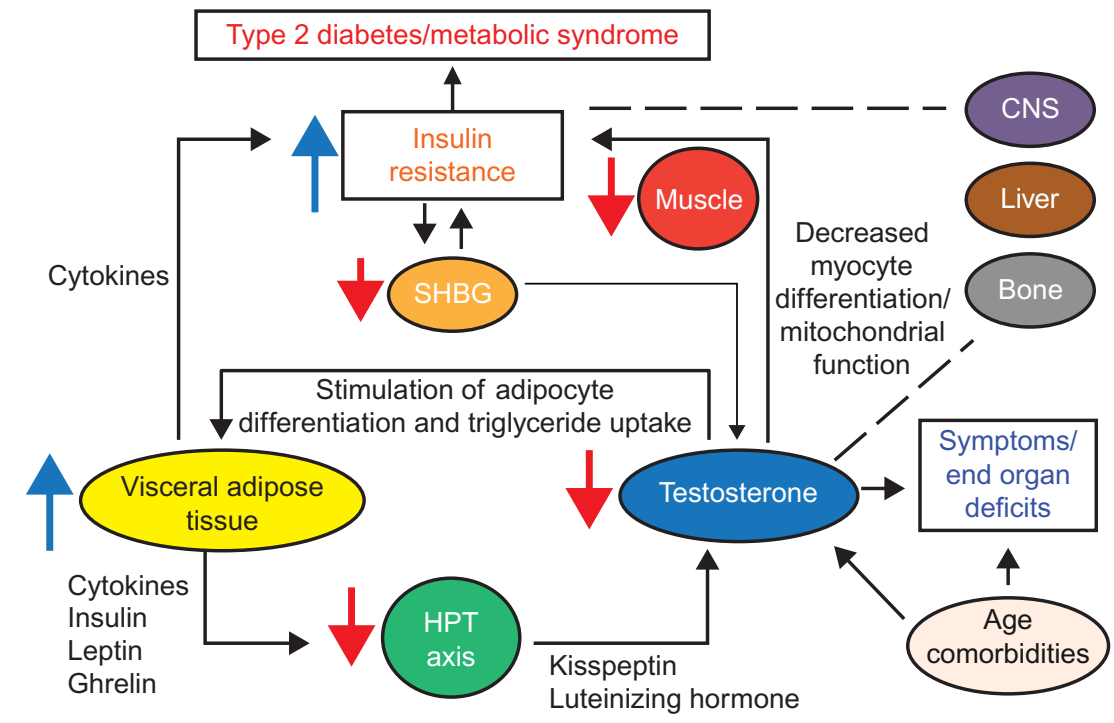

Figure 4

Bi-directional relationship between visceral fat and testosterone: a self-perpetuating cycle promoting insulin resistance. SHBG, sex hormone bindingglobulin; HPT, hypothalamic-pituitary-testicular; for references, see text.

http://joe.endocrinology-journals.org DOI: $10.1530 / \mathrm{JOE}-13-0393$
C 2014 Society for Endocrinology Printed in Great Britain
Published by Bioscientifica Ltd. 
inhibition of the gonadal axis predominantly takes place in the hypothalamus, especially with more severe obesity. Metabolic factors, such as leptin, insulin (via deficiency or resistance) and ghrelin are believed to act at the ventromedial and arcuate nuclei of the hypothalamus to inhibit gonadotropin-releasing hormone (GNRH) secretion from GNRH neurons situated in the preoptic area (Navarro \& Kaiser 2013). While several putative neurocircuits may link these afferent and efferent signals, kisspeptin has emerged as one of the most potent secretagogues of GNRH release (Navarro \& Kaiser 2013). Consistent with the hypothesis that obesity-mediated inhibition of kisspeptin signalling contributes to the suppression of the HPT axis, infusion of a bioactive kisspeptin fragment has been recently shown to robustly increase LH pulsatility, LH levels and circulating testosterone in hypotestosteronaemic men with type 2 diabetes (George et al. 2013).

The inhibitory role of oestradiol on LH secretion, inferred by clinical studies demonstrating an increase in circulating testosterone levels with aromatase inhibitors, has recently come under scrutiny. This is because population-based studies have shown that obese men, whether diabetic (Dhindsa et al. 2011) or not (Huhtaniemi et al. 2012, Yeap et al. 2012a), have lower circulating oestradiol levels than non-diabetic and lean men. These observations do not exclude the possibility that aromatase inhibitors counteract increased paracrine oestradiol actions at the hypothalamus. Interestingly, a recent 16-week study of experimentally induced hypogonadism in healthy men with graded testosterone add-back either with or without concomitant aromatase inhibitor treatment has in fact suggested that low oestradiol (but not low testosterone) may be responsible for the hypogonadismassociated increase in total body and intra-abdominal fat mass (Finkelstein et al. 2013). A smaller study with a similar experimental design found that acute testosterone withdrawal reduced insulin sensitivity independent of body weight, whereas oestradiol withdrawal had no effects
(Rubinow et al. 2012). Clearly, potentially differential actions of testosterone and its metabolite oestradiol on fat mass and insulin sensitivity require further study.

\section{Therapeutic approach to treatment of lowered testosterone levels in men with metabolic disorders}

The bi-directional relationship between low testosterone and insulin resistance is mediated, at least in part, by increased visceral fat (Fig. 4). This suggests that both weight loss as well as testosterone treatment have the potential to break this vicious cycle.

Several lines of evidence (Farooqi et al. 2002, Zumoff et al. 2003, Travison et al. 2008, Tajar et al. 2010, Grossmann 2011, Sartorius et al. 2012, Camacho et al. 2013, Corona et al. 2013a,b, George et al. 2013), summarised in Box 1, suggest that the in the majority of men, suppression of the diabesity-associated HPT axis is functional, and may hence be reversible. Obesity and dysglycaemia and associated comorbidities such as obstructive sleep apnoea (Hoyos et al. 2012b) are important contributors to the suppression of the HPT axis. Therefore, lifestyle modification, weight reduction and treatment of comorbidities are the most logical approach. This is supported by observational studies showing that weight gain and development of diabetes accelerate the age-related decline in testosterone. This suggests that this decline may be decelerated through management of health and lifestyle factors (Travison et al. 2007, Haring et al. 2010).

Several observational and randomised studies reviewed in Grossmann (2011) have shown that weight loss, whether by diet or surgery, leads to substantial increases in testosterone, especially in morbidly obese men. The increase in testosterone was highly proportional to the amount of weight lost. It has been estimated that $10 \%$ weight loss increases testosterone by $2-3 \mathrm{nmol} / \mathrm{l}$.

Box 1 Evidence suggesting that the hypothalamic-pituitary-testicular axis suppression in obese men with metabolic disorders is functional. For individual references, see main text

$55 \%$ of symptomatic androgen deficiency reverted to a normal testosterone or an asymptomatic state after 8-year follow-up, suggesting that androgen deficiency is not a stable state

Modifiable risk factors such as obesity and co-morbidities are more strongly associated with a decline in circulating testosterone levels than age alone

Weight loss can reactivate the hypothalamic-pituitary-testicular axis

Leptin treatment resolves hypogonadism in leptin-deficient men

The hypothalamic-pituitary-testicular axis remains responsive to treatment with aromatase inhibitors or selective oestrogen receptor modulators in obese men

Kisspeptin treatment increases LH secretion, pulse frequency and circulating testosterone levels in hypotestosteronaemic men with type 2 diabetes

http://joe.endocrinology-journals.org DOI: 10.1530/JOE-13-0393
(C) 2014 Society for Endocrinology Printed in Great Britain
Published by Bioscientifica Ltd 
More markedly ( $>30 \%$ ), body weight loss secondary to bariatric surgery can raise testosterone by $>10 \mathrm{nmol} / \mathrm{l}$ (Grossmann 2011).

This has been confirmed by a recent systematic review and meta-analysis of studies that have reported the effects of weight loss on testosterone levels (Corona et al. 2013b). Non-surgical weight loss achieved a mean weight reduction $(9.8 \%)$ in body weight. This led to an increase in total testosterone $(2.87 \mathrm{nmol} / \mathrm{l})$. Surgical weight loss achieved greater reductions in weight (32\%) and more marked increases in circulating testosterone levels $(8.73 \mathrm{nmol} / \mathrm{l})$. Men with diabetes experienced a lesser increase in testosterone compared with men without diabetes. This was likely due to the fact that men with diabetes lost lesser amounts of body weight. In a stepwise logistic regression analysis, only the change in BMI was associated with the change in testosterone (Corona et al. $2013 a, b)$.

More recently, a retrospective analysis of 891 men with impaired glucose tolerance and a mean BMI of $32 \mathrm{~kg} / \mathrm{m}^{2}$ participating in the diabetes prevention programme has been reported. Men randomised to lifestyle modification had a $15 \%(+1.5 \mathrm{nmol} / \mathrm{l})$ increase in their testosterone levels coincident with $7.8 \mathrm{~kg}$ weight loss. This reduced the prevalence of hypoandrogenaemia (defined a total testosterone of $<10.2 \mathrm{nmol} / \mathrm{l}$ ) by almost $50 \%$ $(20.4-11.1 \%(P<0.05))$. In contrast, testosterone levels or hypoandrogenaemia prevalence did not change significantly in men randomised to either placebo or to metformin, who lost $<3 \mathrm{~kg}$ of weight (Dwyer et al. 2012).

The effects of weight changes on the gonadal axis in overweight men (mean BMI $27.6 \mathrm{~kg} / \mathrm{m}^{2}$ ) have also been elegantly demonstrated in a recent observational survey from the EMAS cohort (Camacho et al. 2013). In this longitudinal study, weight loss of $<10 \%$ primarily increased SHBG probably because of improved insulin resistance. This was associated with increases in total but not free testosterone. Weight gain led to the opposite changes. With more substantial weight loss, LH and free testosterone also increased. This suggests that weight loss can lead to genuine reactivation of the gonadal axis by reversal of obesity-associated hypothalamic suppression. Weight loss can also improve quality of live and sexual function in obese men, but whether this is causally related to the associated increase in testosterone levels is not known (Khoo et al. 2010).

There is pre-clinical and observational evidence that chronic hyperglycaemia can inhibit the HPT axis (Cameron et al. 1990, Iranmanesh et al. 2012, Allan 2013). This suggests that improving glycaemic control may increase testosterone levels. This has been demonstrated in a longitudinal analysis of 265 men with diabetes: in men who improved their glycaemic control over time, testosterone levels increased. By contrast, in those men in whom glycaemic control worsened, testosterone decreased (Grossmann et al. 2008).

Men with type 2 diabetes usually have only modest reductions in their testosterone levels. Median circulatory total testosterone levels range from 10.5 to $12.7 \mathrm{nmol} / \mathrm{l}$ (Dhindsa et al. 2004, Kapoor et al. 2007, Grossmann et al. 2008). Therefore, successful weight loss combined with optimisation of glycaemic control may be sufficient to normalise circulating testosterone levels in the majority of such men. Although often difficult to achieve, weight loss, optimisation of diabetic control and assiduous care of comorbidities should remain the first-line approach.

However, whether weight loss, even if successful, can fully reverse the HPT axis suppression is not known. A small recently published longitudinal observational study in 13 obese men with low testosterone levels submitted to bariatric surgery has shown that while ten of the men had free testosterone levels in the normal range 1 year after surgery, in three of the men free testosterone remained in the hypogonadal range, despite substantial weight loss (Aarts et al. 2013). Therefore, testosterone levels should be measured after successful weight loss to identify men with an insufficient rise in their testosterone levels. Such men may have HPT axis pathology unrelated to their obesity, which will require appropriate evaluation and management.

\section{Testosterone treatment in men with metabolic disorders}

Some, but not all uncontrolled studies, reviewed in Grossmann et al. (2010) have suggested beneficial effects of testosterone therapy on glucose metabolism. More recently, two observational studies, one in US Veterans (Shores et al. 2012) the other in diabetic men from the UK (Muraleedharan et al. 2013) have been reported. In both studies, men who were treated with testosterone had a $50 \%$ reduced risk of mortality compared with untreated men. In the Veteran population, the difference in hazard ratio for death was particularly noticeable in the subgroup of men with diabetes (Shores et al. 2012). A more recent, larger retrospective cohort study has reported findings opposite to those of Shores (Shores et al. 2012) and Muraleedharan (Muraleedharan et al. 2013). This study evaluated a cohort of 8709 men with a high burden of comorbidities, including a $50 \%$ prevalence of diabetes

Published by Bioscientifica Ltd 
(Vigen et al. 2013). In this cohort, testosterone therapy was associated with an increased risk of adverse outcomes including all-cause mortality, myocardial infarction and ischaemic stroke (adjusted hazard ratio 1.29, 95\% CI 1.04 to 1.58) (Vigen et al. 2013). In part, the discrepant results may be due to the fact men in the Vigen cohort (Vigen et al. 2013) had a higher burden of comorbidities. Given that one (Basaria et al. 2010), but not all (Srinivas-Shankar et al. 2010), RCTs in men with a similarly high burden of comorbidities reported an increase in cardiovascular events in men randomised to testosterone treatment (see section on Testosterone therapy: potential risks below) (Basaria et al. 2010), testosterone should be used with caution in frail men with multiple comorbidities. The retrospective, non-randomised and non-blinded design of these studies (Shores et al. 2012, Muraleedharan et al. 2013, Vigen et al. 2013) leaves open the possibility for residual confounding and multiple other sources of bias. These have been elegantly summarised by $\mathrm{Wu}$ (2012).

Evidences from placebo-controlled, double-blind randomised-controlled trials examining glycaemic outcomes have to date been inconsistent. There have been ten RCTs in a total of 907 men not selected for diabetes. These men were ageing, overweight and had borderline low baseline testosterone levels (Table 1; Liu et al. 2003, Page et al. 2005, Basu et al. 2007, Bhasin et al. 2007, Allan et al. 2008, 2010, Emmelot-Vonk et al. 2008, Svartberg et al. 2008, Caminiti et al. 2009, Huang et al. 2013). Effects of testosterone therapy on body composition were metabolically favourable with modest decreases in fat mass and increases in lean body mass. Despite this, decreases in insulin resistance were found in only two (Emmelot-Vonk et al. 2008, Caminiti et al. 2009) of the ten trials. This suggests that testosterone has limited effects on glucose metabolism in relatively healthy men with only mildly reduced testosterone.

Six RCTs have been conducted to date specifically in men with diabetes or the metabolic syndrome (Kapoor et al. 2006, Gopal et al. 2010, Kalinchenko et al. 2010, Jones et al. 2011; Tables 1 and 2). One was never unpublished (http://www.solvaypharmaceuticals.com/ static/wma/pdf/1/3/4/4/2/S176.2.101.pdf) and one has been presented in preliminary abstract form (Hackett et al. 2013). Compared with unselected men, these men were more obese and had lower testosterone levels (Table 1). Again, beneficial changes in body composition were reported in most trials. However, they did not consistently translate in major improvements of glucose metabolism. Half of the RCTs showed modest improvements in insulin resistance, comparable roughly with metformin monotherapy. The other half showed no effect. One small study reported an improved in HbA1c (Kapoor et al. 2006). This was not confirmed by most subsequent larger RCTs. However, men enrolled in these RCTs had reasonably well-controlled diabetes even before testosterone treatment was commenced (Table 2).

Table 1 Effects of testosterone therapy on glucose metabolism in randomised controlled clinical trials. Values are median (range). For references, see main text. Data from Grossmann et al. 2010

$\begin{array}{lll}\text { Target } & & \text { Number of participants } \\ \begin{array}{l}\text { Older men not selected } \\ \text { for abnormal glucose } \\ \text { metabolism }\end{array} & & \end{array}$

Men with diabetes and or the metabolic syndrome ${ }^{b}$

Baseline characteristics
Age 67 years (47-74)
BMI $28 \mathrm{~kg} / \mathrm{m}^{2}(26-34)$
TT $11.4 \mathrm{nmol} / \mathrm{l}(8.4-14.7)$

$182(22-220)$
Age 60 years (44-64)

BMI $33 \mathrm{~kg} / \mathrm{m}^{2}(24-35)$

TT $9.3 \mathrm{nmol} / \mathrm{l}(6.7$ to $<13.0)$

$\mathrm{HbA} 1 \mathrm{c}^{c} 7.2 \%(7.0-9.5)$

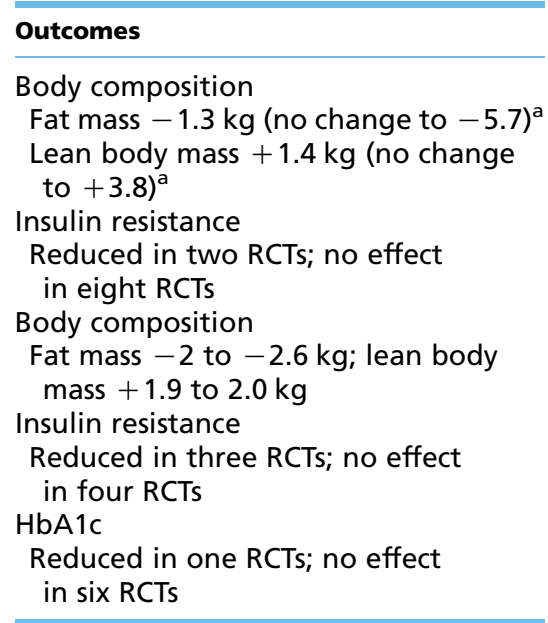

TT, total testosterone.

${ }^{a}$ The total population enrolled in the ten randomised controlled trials (RCTs) of unselected men included 907 participants.

b In six RCTs of men with type 2 diabetes and or the metabolic syndrome 829 participants were enrolled.

'Men with diabetes only.

http://joe.endocrinology-journals.org DOI: 10.1530/JOE-13-0393
(C) 2014 Society for Endocrinology Printed in Great Britain
Published by Bioscientifica Ltd 


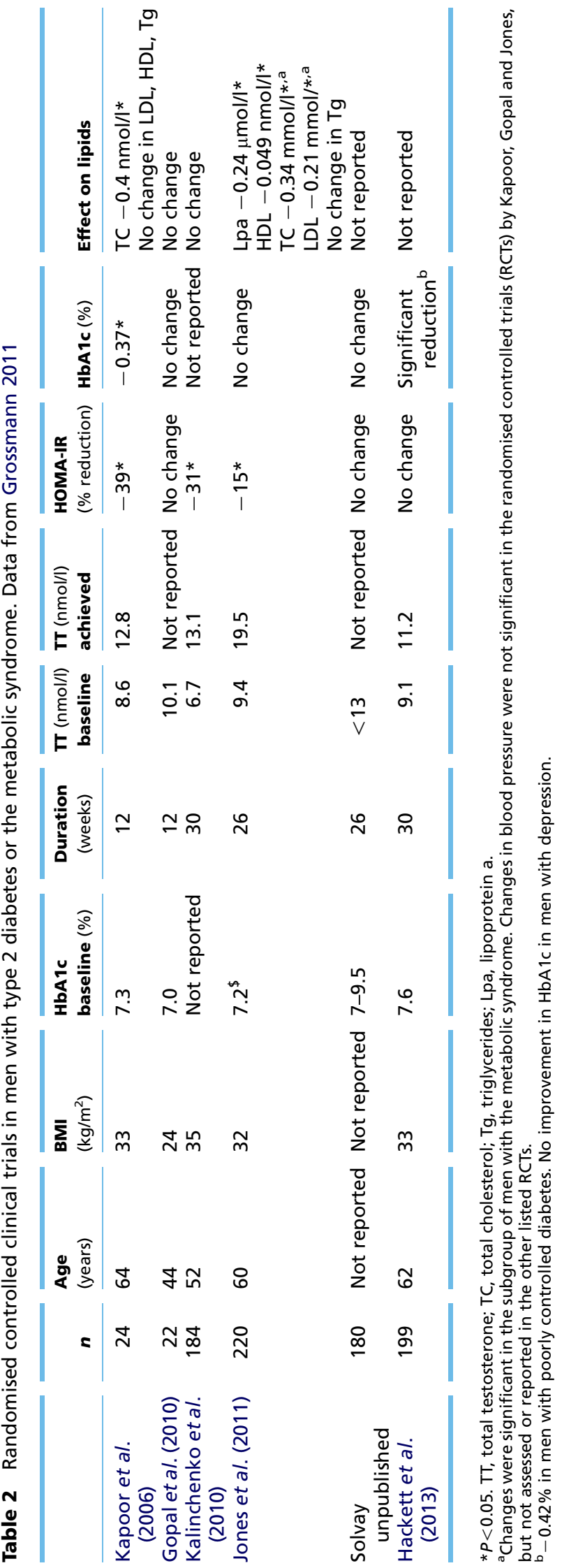

http://joe.endocrinology-journals.org DOI: 10.1530/JOE-13-0393
(C) 2014 Society for Endocrinology Printed in Great Britain
Indeed, a recent, yet to be published RCT (Hackett et al. 2013) has reported a significant reduction in HbA1c in men with poorly controlled diabetes. Therefore, it is conceivable that testosterone treatment may have more significant effects on glucose metabolism in uncontrolled diabetes, akin to what has generally been shown for conventional anti-diabetic medications.

The study by Hackett et al. (2013) also reported that the improvement in HbA1c was observed only in men without depression. This led the authors to hypothesise that depression may mitigate beneficial effects of testosterone therapy on glucose metabolism. Differences in baseline characteristics and baseline circulating testosterone levels among study participants, in the type of testosterone therapy, in the testosterone levels achieved on treatment and in the stringency by which concomitant alterations in anti-glycaemic therapy were controlled for may additionally account for some of the between-trial inconsistencies. Limitations of all RCTs to date include measurement of testosterone by immunoassay rather than by LCMS/MS, and use of surrogate markers of glucose metabolism rather than insulin clamps.

Whether testosterone therapy can enhance the effects of lifestyle measures on glucose metabolism remains unknown. A small, single-blind study found that testosterone treatment augmented the reductions in central adiposity and insulin resistance achieved with lifestyle (Heufelder et al. 2009). However, a subsequent RCT failed to find additive effects of dietary restriction and testosterone therapy on weight loss (Hoyos et al. 2012a).

In summary, the evidence from controlled studies show that testosterone therapy consistently reduces fat mass and increases lean body mass, but inconsistently decreases insulin resistance. At least in men with adequate control of diabetes, testosterone treatment does not improve glycaemic control. Whether testosterone treatment can improve glycaemic control with poorer glycaemic control, or whether it can reduce the risk of developing diabetes in high-risk men requires further study. This latter hypothesis is currently being tested in a multicentre Australian RCT, 'Testosterone Treatment for the Prevention of Type 2 Diabetes Mellitus in High-Risk Men' (T4DM, Australian New Zealand Clinical Trials Registry: ACTRN12612000287831).

There are several potential reasons why testosterone therapy does not improve glucose metabolism despite preclinical and observational data supporting a plausible hypothesis for such an effect. First, men enrolled in the intervention trials RCT had only modestly lowered baseline testosterone levels around the lower limit of the assay

Published by Bioscientifica Ltd. 
references range derived from healthy young men (Tables 1 and 2). Profound testosterone deficiency $(<1 \mathrm{nmol} / \mathrm{l})$ induced by androgen deprivation therapy consistently induces insulin resistance (Smith et al. 2006, Hamilton et al. 2011). This suggests a threshold effect. Observational and experimental studies however have failed to identify a consistent threshold. Instead, they show that the testosterone threshold required to prevent fat accumulation and to maintain insulin sensitivity varies across populations and experimental settings (Singh et al. 2002, Bhasin et al. 2005, Isidori et al. 2005, Zitzmann et al. 2006, Hamilton et al. 2011, Tajar et al. 2012; Table 3). Collectively, these data do not exclude the possibility that men with type 2 diabetes and more profound reductions in testosterone may derive a glycaemic benefit with testosterone therapy. However, marked reductions in testosterone levels are uncommon in men with diabetes. They commonly have only modest reductions in circulating testosterone: mean pooled differences in total testosterone relative to men without diabetes range from $-1.61 \mathrm{nmol} / \mathrm{l}$ (Ding et al. 2006) to $-2.99 \mathrm{nmol} / \mathrm{l}$ (Corona et al. 2010) in meta-analyses. Symptomatic men with unequivocal reductions of testosterone levels should, after an appropriate diagnostic work up, be considered for testosterone therapy irrespective of its effect on glucose metabolism, given the general benefits in such men (Bhasin et al. 2010).

Interestingly, testosterone therapy does not consistently improve glucose metabolism despite a reduction in fat mass and an increase in lean mass. It is possible that these metabolically favourable changes in body composition were too small to alter insulin resistance. However, studies that have reported thresholds for both fat mass and insulin sensitivity suggest that the testosterone level required to prevent fat accumulation may be higher than the level below which insulin resistance increases (Table 3). Studies in men with experimentally induced hypogonadism (Singh et al. 2002) and in male mice lacking a functional androgen receptor either globally (Rana et al. 2011) or selectively in fat (McInnes et al. 2012) also show that effects of testosterone on body composition and glucose metabolism can be dissociated. In part, this may be due to the fact that the effects of testosterone therapy on visceral adiposity, the fat compartment most closely associated with insulin resistance, have been inconsistent: the

Table 3 Testosterone thresholds for maintenance of fat mass and insulin sensitivity

\begin{tabular}{|c|c|}
\hline Author & Method \\
\hline Singh et al. (2002) & $\begin{array}{l}\text { Experimental: induced androgen } \\
\text { deficiency with graded } \\
\text { testosterone add-back (healthy } \\
\text { young men) }\end{array}$ \\
\hline Bhasin et al. (2005) & $\begin{array}{l}\text { Experimental: induced androgen } \\
\text { deficiency with graded } \\
\text { testosterone add-back } \\
\text { (older men) }\end{array}$ \\
\hline $\begin{array}{l}\text { Finkelstein et al. } \\
\quad(2013)\end{array}$ & $\begin{array}{l}\text { Experimental: induced androgen } \\
\text { deficiency with graded } \\
\text { testosterone add-back (healthy } \\
\text { young men) } \pm \text { aromatase } \\
\text { inhibitor co-administration } \\
\text { (healthy young men) }\end{array}$ \\
\hline Zitzmann et al. (2006) & $\begin{array}{l}\text { Observational: community- } \\
\text { dwelling men presenting to an } \\
\text { andrological outpatient } \\
\text { department }\end{array}$ \\
\hline Tajar et al. (2012) & Observational: EMAS cohort \\
\hline Hamilton et al. (2011) & $\begin{array}{l}\text { Observational: men with prostate } \\
\text { cancer receiving androgen } \\
\text { deprivation therapy }\end{array}$ \\
\hline Isidori et al. (2005) & $\begin{array}{l}\text { Meta-analysis of randomised } \\
\text { controlled trials }\end{array}$ \\
\hline
\end{tabular}

Fat mass

TT 10.6

fT 110

TT 6.1

fT 65

TT $13.9^{a}$

Increase in both total and intra-abdominal fat mass)

Obesity $\mathrm{TT}<12.0$

Diabetes TT $<10.0$

Obesity $\mathrm{TT}<10.0$

$\mathrm{TT}<1.0 \mathrm{nmol} / \mathrm{l}$

Increase in total fat mass and in visceral adipose tissue volume Significant decrease with no difference if stratified according to baseline TT $(<10$ and $>10)$

\section{Glycaemia}

Not reported

Not reported

No change at lowest testosterone concentrations: TT 6.1, fT 80

\author{
Metabolic syndrome/insulin \\ resistance $<8.0$ \\ $\mathrm{TT}<1.0 \mathrm{nmol} / \mathrm{l}$
}

Not reported

$\mathrm{TT}$, total testosterone $(\mathrm{nmol} / \mathrm{l}) ; \mathrm{fT}$, free testosterone $(\mathrm{pmol} / \mathrm{l})$.

${ }^{a}$ This study suggested that oestradiol is more important than testosterone to prevent fat accumulation.

http://joe.endocrinology-journals.org DOI: 10.1530/JOE-13-0393
C 2014 Society for Endocrinology Printed in Great Britain
Published by Bioscientifica Ltd. 
majority of RCTs (recently reviewed in Ng Tang Fui et al. (2013a)) showed that testosterone therapy does not reduce visceral fat. Consistent with this, testosterone therapy does not, despite reducing fat mass, increase adiponectin levels, an insulin-sensitising adipokine that is usually inversely associated with fat mass. In fact, androgen deprivation therapy, despite increasing visceral fat mass and in insulin resistance, paradoxically increases adiponectin levels (Hamilton et al. 2011). In addition, testosterone therapy decreases SHBG. SHBG may have biological actions that improve glucose metabolism (Wallace et al. 2013). Future studies should clarify whether effects of testosterone on adiponectin, SHBG and other potential regulators of glucose metabolism, such as undercarboxylated osteocalcin (Yeap 2011), may limit testosterone therapy-mediated improvements in glucose metabolism.

\section{Testosterone, lipids and blood pressure}

In most population-based studies of men with and without metabolic disorders, reviewed recently by Monroe \& Dobs (2013), testosterone is inversely associated with total cholesterol, LDL cholesterol and triglyceride (Tg) levels, but positively associated with HDL cholesterol levels, even if adjusted for confounders. Similar findings have been reported in men with diabetes (Fig. 2; Dhindsa et al. 2004, Kapoor et al. 2007, Grossmann et al. 2008). Although observational studies show a consistent association of low testosterone with adverse lipid profiles, whether testosterone therapy exerts beneficial effects on lipid profiles is less clear. The effects of testosterone treatments on lipid levels have been meta-analysed (Fernandez-Balsells et al. 2010). In this analysis, HDL cholesterol levels were significantly lower in the testosterone group than in the control group (weighted mean difference $-0.49 \mathrm{mg} / \mathrm{dl} ; 95 \% \mathrm{CI}-0.85$ to -0.13 ). There was no statistically significant difference in total cholesterol, LDL cholesterol and Tg levels between the testosterone group and the control group (Fernandez-Balsells et al. 2010). The effects of testosterone treatment on lipids in double-blind placebo-controlled RCTs are shown in Table 2. In the TIMES2 study Jones et al. (2011) found not only a significant decrease in lipoprotein a (Lpa), an independent risk factor for cardiovascular disease, but also a significant decrease in the theoretically protective HDL cholesterol. Patients with metabolic syndrome additionally had reduced total and LDL cholesterol after 6 months of testosterone therapy compared with placebo (Table 2). A recent meta-analysis which included both double-blind placebo-controlled RCTs as well less rigorous intervention trials found that testosterone treatment significantly reduced $\mathrm{Tg}$ levels in men with the metabolic syndrome $(-0.40 \mathrm{nmol} / \mathrm{l} ; 95 \% \mathrm{CI}-0.66,-0.14)$ and in men with diabetes $(-0.60 \mathrm{nmol} / \mathrm{l} ; 95 \% \mathrm{CI}-0.83,-0.37)$. Effects of testosterone treatment on other lipid fractions were not reported (Corona et al. 2013a,b).

In summary, testosterone therapy has been shown to have modest but significant effects on lipid levels in some but not all studies of men with and without disorders of glucose metabolism. Whereas testosterone-induced decreases in total cholesterol, LDL cholesterol and Lpa are expected to reduce cardiovascular risk, testosterone also decreases the levels of the cardio-protective HDL cholesterol. Therefore, the net effect of testosterone therapy on cardiovascular risk remains uncertain.

There is no evidence that testosterone treatment has significant effects on blood pressure, either from the most recent meta-analysis (Fernandez-Balsells et al. 2010) or from individual RCTs specifically enrolling men with the metabolic syndrome and/or diabetes (Table 2).

\section{Testosterone therapy: potential risks}

Potential risks of testosterone therapy have been reviewed in excellent recent reviews (Cunningham \& Toma 2011, Yeap et al. 2012b, Huhtaniemi 2013, Matsumoto 2013, Spitzer et al. 2013). They are summarised only briefly. It is important to note that RCTs and meta-analyses to date have been underpowered to provide definitive outcome data regarding cardiovascular and prostate events. The long-term risks of testosterone therapy are therefore unknown. The overall frequency of serious adverse events in RCTs, considering that these trials included older men with varying degrees of age-related comorbidities, has been low (Fernandez-Balsells et al. 2010).

One meta-analysis has shown increased prostate events, largely driven by PSA increases and protocolmandated prostate biopsies (Calof et al. 2005). Current, albeit limited and preliminary data have not shown evidence that testosterone causes prostate cancer, or that it makes subclinical prostate cancer grow (Grossmann \& Wittert 2012). However, it has been estimated that an RCT of 6000 men treated with testosterone or placebo for 3 years is necessary to detect a $30 \%$ increase in prostate cancer risk with testosterone therapy (Cunningham \& Toma 2011). Yet, the largest completed trials have included $<500$ men, and most have been short term. Because prostate monitoring is recommended during testosterone therapy

Published by Bioscientifica Ltd. 
(Bhasin et al. 2010), concern remains regarding an increased risk of over-diagnosing pre-existing, clinically insignificant prostate cancer, which is highly prevalent in older men.

One meta-analysis has shown a small increase in haematocrit and decrease in HDL cholesterol (FernandezBalsells et al. 2010), theoretically unfavourable changes. One RCT has shown an increase in cardiovascular events with testosterone in relatively frail older men (Basaria et al. 2010). However, another RCT in a similar population of men has not confirmed this finding (Srinivas-Shankar et al. 2010). While previous smaller meta-analyses (Calof et al. 2005, Fernandez-Balsells et al. 2010) have not shown increased risk, the most recent meta-analysis of RCTs including almost 3000 mainly older men did show an increased risk cardiovascular-related events with testosterone therapy (odds ratio 1.54 (95\% CI 1.09 to 2.18)) (Xu et al. 2013). Limitations of this meta-analysis include an overall low number of events, 115 events in 1733 testosterone-treated men (6.6 per 100 men) vs 65 events in 1261 men receiving placebo ( 5.2 per 100 men), and the absence of sensitivity analyses (Xu et al. 2013) to exclude outlier studies (Basaria et al. 2010). In addition, metaanalysed trials were generally small, short-term, and events were heterogeneous. The trials were not designed for evaluating cardiovascular outcomes, with suboptimal ascertainment and adjudication of events. Hence, the data are not definitive.

Finally, compared with otherwise healthy young men with organic androgen deficiency, there may be increased risks in older, obese men because of comorbidities and of decreased testosterone clearance (Zitzmann \& Nieschlag 2007, Coviello et al. 2008, Hoyos et al. 2012a).

\section{Low testosterone and metabolic disorders: summary}

The relationship between low testosterone and metabolic disorders is complex, multi-directional and may involve a number of different mechanisms. These complex relationships are virtually impossible to disentangle. On central component is the inverse association of circulating testosterone with insulin resistance. Figure 3 shows the best-studied mechanisms by which testosterone (either directly and/or indirectly via its metabolites dihydrotestosterone (DHT) or oestradiol) may decrease insulin resistance. Future studies may clarify additional mechanisms, such as effects on energy

Table 4 Summary of the current evidence and recommendations for clinical assessment and management of lowered testosterone in men with metabolic disorders (type 2 diabetes and/or the metabolic syndrome)

Current evidence

1

2

3

4

5 Recommendations for assessment and management

1

2

3

4

5

6 levels health outcomes

If you treat:
Men with metabolic disorders commonly present with non-specific symptoms and modestly low testosterone

Low testosterone identifies an adverse metabolic phenotype and may be associated with end-organ deficits suggesting androgen deficiency

Testosterone increases with weight loss, suggesting that the hypothalamic-pituitary-testicular axis suppression is functional and reversible

In randomised controlled trials of testosterone therapy, metabolically favourable changes in body composition have not consistently translated into improvements of glucose metabolism or other important

Long-term risks of testosterone therapy in men without classical androgen deficiency remain unknown

Measure testosterone in men with metabolic disorders in whom androgen deficiency is suspected clinically Evaluate unequivocally low testosterone levels for an underlying pathological cause and do not assume that hypogonadism is a consequence of metabolic disorders

The first response to the ageing, obese man with metabolic disorders and low-normal testosterone should be the optimisation of life-style measures and glycaemic control, and of established therapies with high level evidence of outcome benefit

Indications for testosterone therapy in men with metabolic disorders should be:

no difference in men without metabolic disorders

reserved for clinically significant symptoms with persistently low testosterone

Testosterone therapy should not be routinely given to men with metabolic disorders and low-normal testosterone until clinical benefit is confirmed by well-conducted clinical trials

discuss uncertainties about risks/benefits

set goals

evaluate for benefit/adverse events

implement standardised monitoring programme

reduced insulin resistance potential collateral benefit http://joe.endocrinology-journals.org DOI: 10.1530/JOE-13-0393 (c) 2014 Society for Endocrinology Printed in Great Britain
Published by Bioscientifica Ltd 
expenditure, inflammation or on changes in physical activity and motivation. Figure 4 shows that increased visceral fat is an important component in the association of low testosterone and insulin resistance. However, given the widespread expression of sex steroid receptors in multiple tissues, cross talk between testosterone and/or DHT and oestradiol, and other organs such as bone, liver or the CNS may play a role. Finally age and, probably more importantly, age-associated comorbidities may not only decrease testosterone levels but also promote insulin resistance.

\section{Conclusions and areas of future research}

The current evidence and recommendations regarding clinical assessment and management are summarised in Table 4. Given the difficulties in diagnosis of androgen deficiency in men with metabolic disorders, future research should focus on the identification of objective, quantifiable markers of androgen deficiency. Such markers may not only aid in diagnosis but may also predict a response to testosterone therapy. However, this hypothesis requires to be tested in clinical trials.

The vast majority of men with metabolic disorders have functional gonadal axis suppression with modest reductions in testosterone levels. This may be reversible with loss and optimisation of comorbidities. Therefore, identification and treatment of comorbidities and lifestyle measure with emphasis on weight loss remain the first-line approach to therapy of lowered testosterone levels in men with metabolic disorders. However, should well-conducted RCTs provide favourable evidence regarding the risk-benefit ratio, testosterone therapy, be it replacement or pharmacological, may become an option in such men. Future RCTs should evaluate whether, in obese men, testosterone treatment will increase the success rate of a lifestyle programme targeted at weight loss. Currently, testosterone treatment may, after discussion regarding the experimental nature of this treatment, be considered either when lifestyle measures fail or are insufficient to restore circulating testosterone to levels sufficient to prevent deleterious effects of androgen deficiency. However, what constitutes a sufficient circulating testosterone level is unknown. This level will vary not only across individuals depending on age, clinical and genetic characteristics, but also across different tissues. In addition, relative roles of testosterone derivatives such as DHT and oestradiol in regulation of body composition and glucose metabolism should be evaluated: recent evidence that fat accumulation may be oestradiol-, rather than testosterone-dependent (Finkelstein et al. 2013). To clarify the apparent paradox why testosterone therapy-induced metabolically favourable changes in body composition do not consistently translate into improvements in glucose metabolism, testosterone effects on visceral fat mass as well as on potential insulin sensitisers such as adiponectin, SHBG and undercarboxylated osteocalcin (Lee et al. 2007) require further study. Future clinical trials assessing the effects of testosterone therapy should focus on men with more marked reductions, larger amount of visceral fat and less well-controlled diabetes. However, marked reductions in testosterone are uncommon even in men with metabolic disorders. They may reflect concomitant authentic androgen deficiency, which requires treatment in its own right. Whether testosterone treatment, be it long term or only temporary, has added benefit to the implementation of lifestyle measures should be assessed in controlled trials.

\section{Declaration of interest}

The author declares that there is no conflict of interest that could be perceived as prejudicing the impartiality of the review.

\section{Funding}

M G was supported by a National Health and Medical Research Council of Australia Career Development Fellowship (\# 1024139).

\section{References}

Aarts E, van Wageningen B, Loves S, Janssen I, Berends F, Sweep F \& de Boer H 2013 Gonadal status and outcome of bariatric surgery in obese men. Clinical Endocrinology [in press]. (doi:10.1111/cen.12366)

Allan CA 2013 Sex steroids and glucose metabolism. Asian Journal of Andrology [in press].

Allan CA, Strauss BJ, Burger HG, Forbes EA \& McLachlan RI 2008 Testosterone therapy prevents gain in visceral adipose tissue and loss of skeletal muscle in nonobese aging men. Journal of Clinical Endocrinology and Metabolism 93 139-146. (doi:10.1210/jc.2007-1291)

Allan CA, Strauss BJG, Forbes EA \& McLachlan RI 2010 Testosterone therapy improves body composition and metabolic parameters in obese aging men: results of a placebo-controlled randomized controlled trial. 92nd Annual Meeting of the Endocrine Society, San Diego P2-455.

Araujo AB, Dixon JM, Suarez EA, Murad MH, Guey LT \& Wittert GA 2011 Clinical review: endogenous testosterone and mortality in men: a systematic review and meta-analysis. Journal of Clinical Endocrinology and Metabolism 96 3007-3019. (doi:10.1210/jc.2011-1137)

Basaria S, Coviello AD, Travison TG, Storer TW, Farwell WR, Jette AM, Eder R, Tennstedt S, Ulloor J, Zhang A et al. 2010 Adverse events associated with testosterone administration. New England Journal of Medicine 363 109-122. (doi:10.1056/NEJMoa1000485)

Basu R, Dalla Man C, Campioni M, Basu A, Nair KS, Jensen MD, Khosla S, Klee G, Toffolo G, Cobelli C et al. 2007 Effect of 2 years of testosterone replacement on insulin secretion, insulin action, glucose effectiveness, hepatic insulin clearance, and postprandial glucose turnover in elderly men. Diabetes Care 30 1972-1978. (doi:10.2337/dc07-0359) 
Bhasin S, Woodhouse L, Casaburi R, Singh AB, Mac RP, Lee M, Yarasheski KE, Sinha-Hikim I, Dzekov C, Dzekov J et al. 2005 Older men are as responsive as young men to the anabolic effects of graded doses of testosterone on the skeletal muscle. Journal of Clinical Endocrinology and Metabolism 90 678-688. (doi:10.1210/jc.2004-1184)

Bhasin S, Calof OM, Storer TW, Lee ML, Mazer NA, Jasuja R, Montori VM, Gao W \& Dalton JT 2006 Drug insight: testosterone and selective androgen receptor modulators as anabolic therapies for chronic illness and aging. Nature Clinical Practice. Endocrinology \& Metabolism 2 146-159. (doi:10.1038/ncpendmet0120)

Bhasin S, Parker RA, Sattler F, Haubrich R, Alston B, Umbleja T \& Shikuma CM 2007 Effects of testosterone supplementation on whole body and regional fat mass and distribution in human immunodeficiency virusinfected men with abdominal obesity. Journal of Clinical Endocrinology and Metabolism 92 1049-1057. (doi:10.1210/jc.2006-2060)

Bhasin S, Cunningham GR, Hayes FJ, Matsumoto AM, Snyder PJ, Swerdloff RS \& Montori VM 2010 Testosterone therapy in men with androgen deficiency syndromes: an endocrine society clinical practice guideline. Journal of Clinical Endocrinology and Metabolism 95 2536-2559. (doi:10.1210/jc.2009-2354)

Bhasin S, Jasjua GK, Pencina M, D'Agostino R Sr, Coviello AD, Vasan RS \& Travison TG 2011a Sex hormone-binding globulin, but not testosterone, is associated prospectively and independently with incident metabolic syndrome in men: the framingham heart study. Diabetes Care 34 2464-2470. (doi:10.2337/dc11-0888)

Bhasin S, Pencina M, Jasuja GK, Travison TG, Coviello A, Orwoll E, Wang PY, Nielson C, Wu F, Tajar A et al. 2011b Reference ranges for testosterone in men generated using liquid chromatography tandem mass spectrometry in a community-based sample of healthy nonobese young men in the Framingham Heart Study and applied to three geographically distinct cohorts. Journal of Clinical Endocrinology and Metabolism 96 2430-2439. (doi:10.1210/jc.2010-3012)

Biswas M, Hampton D, Newcombe RG \& Rees DA 2012 Total and free testosterone concentrations are strongly influenced by age and central obesity in men with type 1 and type 2 diabetes but correlate weakly with symptoms of androgen deficiency and diabetes-related quality of life. Clinical Endocrinology 76 665-673. (doi:10.1111/j.1365-2265.2011. 04196.x)

Bonnet F, Velayoudom Cephise FL, Gautier A, Dubois S, Massart C, Camara A, Larifla L, Balkau B \& Ducluzeau PH 2013 Role of sex steroids, intrahepatic fat and liver enzymes in the association between SHBG and metabolic features. Clinical Endocrinology 79 517-522. (doi:10.1111/cen.12089)

Calof OM, Singh AB, Lee ML, Kenny AM, Urban RJ, Tenover JL \& Bhasin S 2005 Adverse events associated with testosterone replacement in middle-aged and older men: a meta-analysis of randomized, placebocontrolled trials. Journals of Gerontology Series A: Biological Sciences and Medical Sciences 60 1451-1457. (doi:10.1093/gerona/60.11.1451)

Camacho EM, Huhtaniemi IT, O’Neill TW, Finn JD, Pye SR, Lee DM, Tajar A, Bartfai G, Boonen S, Casanueva FF et al. 2013 Age-associated changes in hypothalamic-pituitary-testicular function in middle-aged and older men are modified by weight change and lifestyle factors: longitudinal results from the European Male Ageing Study. European Journal of Endocrinology 168 445-455. (doi:10.1530/EJE-12-0890)

Cameron DF, Rountree J, Schultz RE, Repetta D \& Murray FT 1990 Sustained hyperglycemia results in testicular dysfunction and reduced fertility potential in BBWOR diabetic rats. American Journal of Physiology 259 E881-E889.

Caminiti G, Volterrani M, Iellamo F, Marazzi G, Massaro R, Miceli M, Mammi C, Piepoli M, Fini M \& Rosano GM 2009 Effect of long-acting testosterone treatment on functional exercise capacity, skeletal muscle performance, insulin resistance, and baroreflex sensitivity in elderly patients with chronic heart failure a double-blind, placebo-controlled, randomized study. Journal of the American College of Cardiology $\mathbf{5 4}$ 919-927. (doi:10.1016/j.jacc.2009.04.078)
Caronia LM, Dwyer AA, Hayden D, Amati F, Pitteloud N \& Hayes FJ 2013 Abrupt decrease in serum testosterone levels after an oral glucose load in men: implications for screening for hypogonadism. Clinical Endocrinology 78 291-296. (doi:10.1111/j.1365-2265.2012.04486.x)

Corona G, Monami M, Rastrelli G, Aversa A, Sforza A, Lenzi A, Forti G, Mannucci E \& Maggi M 2010 Type 2 diabetes mellitus and testosterone: a meta-analysis study. International Journal of Andrology 34 528-540. (doi:10.1111/j.1365-2605.2010.01117.x)

Corona G, Monami M, Rastrelli G, Aversa A, Tishova Y, Saad F, Lenzi A, Forti G, Mannucci E \& Maggi M 2011 Testosterone and metabolic syndrome: a meta-analysis study. Journal of Sexual Medicine 8 272-283. (doi:10.1111/j.1743-6109.2010.01991.x)

Corona G, Rastrelli G \& Maggi M 2013a Diagnosis and treatment of late-onset hypogonadism: systematic review and meta-analysis of TRT outcomes. Best Practice \& Research. Clinical Endocrinology \& Metabolism 27 557-579. (doi:10.1016/j.beem.2013.05.002)

Corona G, Rastrelli G, Monami M, Saad F, Luconi M, Lucchese M, Facchiano E, Sforza A, Forti G, Mannucci E et al. 2013b Body weight loss reverts obesity-associated hypogonadotropic hypogonadism: a systematic review and meta-analysis. European Journal of Endocrinology 168 829-843. (doi:10.1530/EJE-12-0955)

Coviello AD, Kaplan B, Lakshman KM, Chen T, Singh AB \& Bhasin S 2008 Effects of graded doses of testosterone on erythropoiesis in healthy young and older men. Journal of Clinical Endocrinology and Metabolism 93 914-919. (doi:10.1210/jc.2007-1692)

Cunningham GR \& Toma SM 2011 Clinical review: why is androgen replacement in males controversial? Journal of Clinical Endocrinology and Metabolism 96 38-52. (doi:10.1210/jc.2010-0266)

Dandona P \& Dhindsa S 2011 Update: hypogonadotropic hypogonadism in type 2 diabetes and obesity. Journal of Clinical Endocrinology and Metabolism 96 2643-2651. (doi:10.1210/jc.2010-2724)

Dhindsa S, Prabhakar S, Sethi M, Bandyopadhyay A, Chaudhuri A \& Dandona P 2004 Frequent occurrence of hypogonadotropic hypogonadism in type 2 diabetes. Journal of Clinical Endocrinology and Metabolism 89 5462-5468. (doi:10.1210/jc.2004-0804)

Dhindsa S, Bhatia V, Dhindsa G, Chaudhuri A, Gollapudi GM \& Dandona P 2007 The effects of hypogonadism on body composition and bone mineral density in type 2 diabetic patients. Diabetes Care 30 1860-1861. (doi:10.2337/dc07-0337)

Dhindsa S, Miller MG, McWhirter CL, Mager DE, Ghanim H, Chaudhuri A \& Dandona P 2010 Testosterone concentrations in diabetic and nondiabetic obese men. Diabetes Care 33 1186-1192. (doi:10.2337/ dc09-1649)

Dhindsa S, Furlanetto R, Vora M, Ghanim H, Chaudhuri A \& Dandona P 2011 Low estradiol concentrations in men with subnormal testosterone concentrations and type 2 diabetes. Diabetes Care 34 1854-1859. (doi:10.2337/dc11-0208)

Ding EL, Song Y, Malik VS \& Liu S 2006 Sex differences of endogenous sex hormones and risk of type 2 diabetes: a systematic review and metaanalysis. Journal of the American Medical Association 295 1288-1299. (doi:10.1001/jama.295.11.1288)

Ding EL, Song Y, Manson JE, Hunter DJ, Lee CC, Rifai N, Buring JE, Gaziano JM \& Liu S 2009 Sex hormone-binding globulin and risk of type 2 diabetes in women and men. New England Journal of Medicine 361 1152-1163. (doi:10.1056/NEJMoa0804381)

Dwyer AA, Caronia LM, Lee H, Nathan DM \& Hayes FJ 2012 Lifestyle modification can reverse hypogonadism in men with impaired glucose tolerance in the diabetes prevention program. Endocrine Reviews 33 OR28.3.

Emmelot-Vonk MH, Verhaar HJ, Nakhai Pour HR, Aleman A, Lock TM, Bosch JL, Grobbee DE \& van der Schouw YT 2008 Effect of testosterone supplementation on functional mobility, cognition, and other parameters in older men: a randomized controlled trial. Journal of the American Medical Association 299 39-52. (doi:10.1001/jama. 2007.51) 
Farooqi IS, Matarese G, Lord GM, Keogh JM, Lawrence E, Agwu C, Sanna V, Jebb SA, Perna F, Fontana S et al. 2002 Beneficial effects of leptin on obesity, T cell hyporesponsiveness, and neuroendocrine/metabolic dysfunction of human congenital leptin deficiency. Journal of Clinical Investigation 110 1093-1103.

Fernandez-Balsells MM, Murad MH, Lane M, Lampropulos JF, Albuquerque F, Mullan RJ, Agrwal N, Elamin MB, Gallegos-Orozco JF, Wang AT et al. 2010 Clinical review 1: adverse effects of testosterone therapy in adult men: a systematic review and meta-analysis. Journal of Clinical Endocrinology and Metabolism 95 2560-2575. (doi:10.1210/jc.2009-2575)

Fernando SM, Rao P, Niel L, Chatterjee D, Stagljar M \& Monks DA 2010 Myocyte androgen receptors increase metabolic rate and improve bodycomposition by reducing fat mass. Endocrinology 151 3125-3132. (doi:10.1210/en.2010-0018)

Finkelstein JS, Lee H, Burnett-Bowie SAM, Pallais JC, Yu EW, Borges LF, Jones BF, Barry CV, Wulczyn KE, Thomas BJ et al. 2013 Gonadal steroids and body composition, strength, and sexual function in men. New England Journal of Medicine 369 1011-1022. (doi:10.1056/ NEJMoa1206168)

George JT, Veldhuis JD, Tena-Sempere M, Millar RP \& Anderson RA 2013 Exploring the pathophysiology of hypogonadism in men with type 2 diabetes: kisspeptin-10 stimulates serum testosterone and LH secretion in men with type 2 diabetes and mild biochemical hypogonadism. Clinical Endocrinology 79 100-104. (doi:10.1111/cen.12103)

Gopal RA, Bothra N, Acharya SV, Ganesh HK, Bandgar TR, Menon PS \& Shah NS 2010 Treatment of hypogonadism with testosterone in patients with type 2 diabetes mellitus. Endocrine Practice 16 570-576. (doi:10.4158/EP09355.OR)

Grossmann M 2011 Low testosterone in men with type 2 diabetes: significance and treatment. Journal of Clinical Endocrinology and Metabolism 96 2341-2353. (doi:10.1210/jc.2011-0118)

Grossmann M \& Wittert G 2012 Androgens, diabetes and prostate cancer. Endocrine-Related Cancer 19 F47-F62. (doi:10.1530/ERC-12-0067)

Grossmann M \& Zajac JD 2011a Androgen deprivation therapy in men with prostate cancer: how should the side effects be monitored and treated? Clinical Endocrinology 74 289-293. (doi:10.1111/j.1365-2265. 2010.03939.x)

Grossmann M \& Zajac JD $2011 b$ Management of side effects of androgen deprivation therapy. Endocrinology and Metabolism Clinics of North America 40 655-671. (doi:10.1016/j.ecl.2011.05.004)

Grossmann M, Thomas MC, Panagiotopoulos S, Sharpe K, Macisaac RJ, Clarke S, Zajac JD \& Jerums G 2008 Low testosterone levels are common and associated with insulin resistance in men with diabetes. Journal of Clinical Endocrinology and Metabolism 93 1834-1840. (doi:10.1210/jc. 2007-2177)

Grossmann M, Panagiotopolous S, Sharpe K, MacIsaac RJ, Clarke S, Zajac JD, Jerums G \& Thomas MC 2009 Low testosterone and anaemia in men with type 2 diabetes. Clinical Endocrinology 70 547-553. (doi:10.1111/j. 1365-2265.2008.03357.x)

Grossmann M, Gianatti EJ \& Zajac JD 2010 Testosterone and type 2 diabetes. Current Opinion in Endocrinology, Diabetes, and Obesity 17 247-256. (doi:10.1097/MED.0b013e32833919cf)

Grossmann M, Hoermann R, Gani L, Chan I, Cheung A, Gow PJ, Li A, Zajac JD $\&$ Angus P 2012 Low testosterone levels as an independent predictor of mortality in men with chronic liver disease. Clinical Endocrinology 77 323-328. (doi:10.1111/j.1365-2265.2012.04347.x)

Groth KA, Skakkebaek A, Host C, Gravholt CH \& Bojesen A 2013 Clinical review: Klinefelter syndrome - a clinical update. Journal of Clinical Endocrinology and Metabolism 98 20-30. (doi:10.1210/jc.2012-2382)

Hackett G, Cole N, Bhartia M, Kennedy D, Raju J, Wilkinson P \& the BLAST Study Group 2013 Testosterone replacement therapy improves metabolic parameters in hypogonadal men with type 2 diabetes but not in men with coexisting depression: the BLAST study. Journal of Sexual Medicine [in press]. (doi:10.1111/jsm.12404)

Hamilton EJ, Gianatti E, Strauss BJ, Wentworth J, Lim-Joon D, Bolton D, Zajac JD \& Grossmann M 2011 Increase in visceral and subcutaneous abdominal fat in men with prostate cancer treated with androgen deprivation therapy. Clinical Endocrinology 74 377-383. (doi:10.1111/ j.1365-2265.2010.03942.x)

Hanchang W, Semprasert N, Limjindaporn T, Yenchitsomanus PT \& Kooptiwut S 2013 Testosterone protects against glucotoxicity induced apoptosis of pancreatic $\beta$-cells (INS-1) and male mouse pancreatic islets. Endocrinology 154 4058-4067. (doi:10.1210/en.2013-1351)

Haring R, Ittermann T, Volzke H, Krebs A, Zygmunt M, Felix SB, Grabe HJ, Nauck M \& Wallaschofski H 2010 Prevalence, incidence and risk factors of testosterone deficiency in a population-based cohort of men: results from the study of health in Pomerania. Aging Male 13 247-257. (doi:10.3109/13685538.2010.487553)

Haring R, Teumer A, Volker U, Dorr M, Nauck M, Biffar R, Volzke H, Baumeister SE \& Wallaschofski H 2013 Mendelian randomization suggests non-causal associations of testosterone with cardiometabolic risk factors and mortality. Andrology 1 17-23. (doi:10.1111/j.2047-2927. 2012.00002.x)

Hazlehurst JM, Armstrong MJ, Sherlock M, Rowe IA, O'Reilly MW, Franklyn JA, Stewart PM \& Tomlinson JW 2013 A comparative quality assessment of evidence-based clinical guidelines in endocrinology. Clinical Endocrinology 78 183-190. (doi:10.1111/j.1365-2265.2012.04441.x)

Heufelder AE, Saad F, Bunck MC \& Gooren L 2009 Fifty-two-week treatment with diet and exercise plus transdermal testosterone reverses the metabolic syndrome and improves glycemic control in men with newly diagnosed type 2 diabetes and subnormal plasma testosterone. Journal of Andrology 30 726-733. (doi:10.2164/jandrol.108.007005)

Hoyos CM, Killick R, Yee BJ, Grunstein RR \& Liu PY 2012a Effects of testosterone therapy on sleep and breathing in obese men with severe obstructive sleep apnoea: a randomized placebo-controlled trial. Clinical Endocrinology 77 599-607. (doi:10.1111/j.1365-2265.2012. 04413.x)

Hoyos CM, Yee BJ, Phillips CL, Machan EA, Grunstein RR \& Liu PY $2012 b$ Body compositional and cardiometabolic effects of testosterone therapy in obese men with severe obstructive sleep apnoea: a randomised placebo-controlled trial. European Journal of Endocrinology 167 531-541. (doi:10.1530/EJE-12-0525)

Huang G, Bhasin S, Tang ER, Aakil A, Anderson SW, Jara H, Davda M, Travison TG \& Basaria S 2013 Effect of testosterone administration on liver fat in older men with mobility limitation: results from a randomized controlled trial. Journals of Gerontology Series A: Biological Sciences and Medical Sciences 68 954-959. (doi:10.1093/gerona/gls259)

Huhtaniemi I 2013 Late-onset hypogonadism; current concepts and controversies of pathogenesis, diagnosis and treatment. Asian Journal of Andrology [in press].

Huhtaniemi IT, Tajar A, Lee DM, O’Neill TW, Finn JD, Bartfai G, Boonen S, Casanueva FF, Giwercman A, Han TS et al. 2012 Comparison of serum testosterone and estradiol measurements in 3174 European men using platform immunoassay and mass spectrometry; relevance for the diagnostics in aging men. European Journal of Endocrinology 166 983-991. (doi:10.1530/EJE-11-1051)

Iranmanesh A, Lawson D \& Veldhuis JD 2012 Glucose ingestion acutely lowers pulsatile LH and basal testosterone secretion in men. American Journal of Physiology. Endocrinology and Metabolism 302 E724-E730. (doi:10.1152/ajpendo.00520.2011)

Isidori AM, Giannetta E, Greco EA, Gianfrilli D, Bonifacio V, Isidori A, Lenzi A \& Fabbri A 2005 Effects of testosterone on body composition, bone metabolism and serum lipid profile in middle-aged men: a metaanalysis. Clinical Endocrinology 63 280-293. (doi:10.1111/j.1365-2265. 2005.02339.x)

Jones TH, Arver S, Behre HM, Buvat J, Meuleman E, Moncada I, Morales AM, Volterrani M, Yellowlees A, Howell JD et al. 2011 Testosterone replacement in hypogonadal men with type 2 diabetes and/or metabolic syndrome (the TIMES2 Study). Diabetes Care 34 828-847. (doi:10.2337/dc10-1233)

Kalinchenko SY, Tishova YA, Mskhalaya GJ, Gooren LJ, Giltay EJ \& Saad F 2010 Effects of testosterone supplementation on markers of the 
metabolic syndrome and inflammation in hypogonadal men with the metabolic syndrome: the double-blinded placebo-controlled Moscow study. Clinical Endocrinology 73 602-612. (doi:10.1111/j.1365-2265. 2010.03845.x)

Kapoor D, Goodwin E, Channer KS \& Jones TH 2006 Testosterone replacement therapy improves insulin resistance, glycaemic control, visceral adiposity and hypercholesterolaemia in hypogonadal men with type 2 diabetes. European Journal of Endocrinology 154 899-906. (doi:10.1530/eje.1.02166)

Kapoor D, Aldred H, Clark S, Channer KS \& Jones TH 2007 Clinical and biochemical assessment of hypogonadism in men with type 2 diabetes: correlations with bioavailable testosterone and visceral adiposity. Diabetes Care 30 911-917. (doi:10.2337/dc06-1426)

Kelly DM \& Jones TH 2013 Testosterone: a metabolic hormone in health and disease. Journal of Endocrinology 217 R25-R45. (doi:10.1530/ JOE-12-0455)

Khoo J, Piantadosi C, Worthley S \& Wittert GA 2010 Effects of a low-energy diet on sexual function and lower urinary tract symptoms in obese men. International Journal of Obesity 34 1396-1403. (doi:10.1038/ ijo.2010.76)

Kupelian V, Page ST, Araujo AB, Travison TG, Bremner WJ \& McKinlay JB 2006 Low sex hormone-binding globulin, total testosterone, and symptomatic androgen deficiency are associated with development of the metabolic syndrome in nonobese men. Journal of Clinical Endocrinology and Metabolism 91 843-850. (doi:10.1210/jc.2005-1326)

Laaksonen DE, Niskanen L, Punnonen K, Nyyssonen K, Tuomainen TP, Valkonen VP \& Salonen JT 2005 The metabolic syndrome and smoking in relation to hypogonadism in middle-aged men: a prospective cohort study. Journal of Clinical Endocrinology and Metabolism 90 712-719. (doi:10.1210/jc.2004-0970)

Lee NK, Sowa H, Hinoi E, Ferron M, Ahn JD, Confavreux C, Dacquin R, Mee PJ, McKee MD, Jung DY et al. 2007 Endocrine regulation of energy metabolism by the skeleton. Cell 130 456-469. (doi:10.1016/j.cell. 2007.05.047)

Lin HY, Yu IC, Wang RS, Chen YT, Liu NC, Altuwaijri S, Hsu CL, Ma WL, Jokinen J, Sparks JD et al. 2008 Increased hepatic steatosis and insulin resistance in mice lacking hepatic androgen receptor. Hepatology $\mathbf{4 7}$ 1924-1935. (doi:10.1002/hep.22252)

Liu PY, Wishart SM, Celermajer DS, Jimenez M, Pierro ID, Conway AJ \& Handelsman DJ 2003 Do reproductive hormones modify insulin sensitivity and metabolism in older men? A randomized, placebocontrolled clinical trial of recombinant human chorionic gonadotropin European Journal of Endocrinology 148 55-66. (doi:10.1530/eje.0.1480055)

Marin P, Oden B \& Bjorntorp P 1995 Assimilation and mobilization of triglycerides in subcutaneous abdominal and femoral adipose tissue in vivo in men: effects of androgens. Journal of Clinical Endocrinology and Metabolism 80 239-243. (doi:10.1210/jc.80.1.239)

Matsumoto AM 2013 Testosterone administration in older men. Endocrinology and Metabolism Clinics of North America 42 271-286. (doi:10.1016/j.ecl.2013.02.011)

McInnes KJ, Smith LB, Hunger NI, Saunders PT, Andrew R \& Walker BR 2012 Deletion of the androgen receptor in adipose tissue in male mice elevates retinol binding protein 4 and reveals independent effects on visceral fat mass and on glucose homeostasis. Diabetes 61 1072-1081. (doi:10.2337/db11-1136)

McLachlan RI 2010 Certainly more guidelines than rules. Journal of Clinical Endocrinology and Metabolism 95 2610-2613. (doi:10.1210/jc.2010-0838)

Monroe KA \& Dobs AS 2013 The effects of androgens on lipids. Current Opinion in Endocrinology, Diabetes, and Obesity 20 132-139. (doi:10.1097/MED.0b013e32835edb71)

Muraleedharan V, Marsh H, Kapoor D, Channer KS \& Jones TH 2013 Testosterone deficiency is associated with increased risk of mortality and testosterone replacement improves survival in men with type 2 diabetes. European Journal of Endocrinology 169 725-733. (doi:10.1530/ EJE-13-0321)
Navarro VM \& Kaiser UB 2013 Metabolic influences on neuroendocrine regulation of reproduction. Current Opinion in Endocrinology, Diabetes, and Obesity 20 335-341.

Ng Tang Fui M, Dupuis P \& Grossmann M 2013a Lowered testosterone in male obesity: mechanisms, morbidity and management. Asian Journal of Andrology [in press].

$\mathrm{Ng}$ Tang Fui M, Hoermann R, Cheung AS, Gianatti E, Zajac JD \& Grossmann M 2013b Obesity and age as dominant correlates of low testosterone in men irrespective of diabetes status. Andrology $\mathbf{1}$ 906-912. (doi:10.1111/j.2047-2927.2013.00124.x)

Oury F, Sumara G, Sumara O, Ferron M, Chang H, Smith CE, Hermo L, Suarez S, Roth BL, Ducy P et al. 2011 Endocrine regulation of male fertility by the skeleton. Cell 144 769-809. (doi:10.1016/j.cell.2011.02.004)

Page ST, Amory JK, Bowman FD, Anawalt BD, Matsumoto AM, Bremner WJ \& Tenover JL 2005 Exogenous testosterone (T) alone or with finasteride increases physical performance, grip strength, and lean body mass in older men with low serum T. Journal of Clinical Endocrinology and Metabolism 90 1502-1510. (doi:10.1210/jc.2004-1933)

Pitteloud N, Mootha VK, Dwyer AA, Hardin M, Lee H, Eriksson KF, Tripathy D, Yialamas M, Groop L, Elahi D et al. 2005 Relationship between testosterone levels, insulin sensitivity, and mitochondrial function in men. Diabetes Care 28 1636-1642. (doi:10.2337/diacare.28.7.1636)

Rabiee A, Dwyer AA, Caronia LM, Hayes FJ, Yialamas MA, Andersen DK, Thomas B, Torriani M \& Elahi D 2010 Impact of acute biochemical castration on insulin sensitivity in healthy adult men. Endocrine Research 35 71-84. (doi:10.3109/07435801003705601)

Rana K, Fam BC, Clarke MV, Pang TP, Zajac JD \& MacLean HE 2011 Increased adiposity in DNA binding-dependent androgen receptor knockout male mice associated with decreased voluntary activity and not insulin resistance. American Journal of Physiology. Endocrinology and Metabolism 301 E767-E778. (doi:10.1152/ajpendo.00584.2010)

Rao PM, Kelly DM \& Jones TH 2013 Testosterone and insulin resistance in the metabolic syndrome and T2DM in men. Nature Reviews. Endocrinology 9 479-493. (doi:10.1038/nrendo.2013.122)

Rastrelli G, Corona G, Vignozzi L, Maseroli E, Silverii A, Monami M, Mannucci E, Forti G \& Maggi M 2013 Serum PSA as a predictor of testosterone deficiency. Journal of Sexual Medicine 10 2518-2528.

Rubinow KB, Snyder CN, Amory JK, Hoofnagle AN \& Page ST 2012 Acute testosterone deprivation reduces insulin sensitivity in men. Clinical Endocrinology 76 281-288. (doi:10.1111/j.1365-2265.2011.04189.x)

Santosa S, Khosla S, McCready LK \& Jensen MD 2010 Effects of estrogen and testosterone on resting energy expenditure in older men. Obesity 18 2392-2394. (doi:10.1038/oby.2010.98)

Sartorius G, Spasevska S, Idan A, Turner L, Forbes E, Zamojska A, Allan CA, Ly LP, Conway AJ, McLachlan RI et al. 2012 Serum testosterone, dihydrotestosterone and estradiol concentrations in older men self-reporting very good health: the healthy man study. Clinical Endocrinology 77 755-763. (doi:10.1111/j.1365-2265.2012.04432.x)

Shores MM, Smith NL, Forsberg CW, Anawalt BD \& Matsumoto AM 2012 Testosterone treatment and mortality in men with low testosterone levels. Journal of Clinical Endocrinology and Metabolism 97 2050-2058. (doi:10.1210/jc.2011-2591)

Singh AB, Hsia S, Alaupovic P, Sinha-Hikim I, Woodhouse L, Buchanan TA, Shen R, Bross R, Berman N \& Bhasin S 2002 The effects of varying doses of $\mathrm{T}$ on insulin sensitivity, plasma lipids, apolipoproteins, and C-reactive protein in healthy young men. Journal of Clinical Endocrinology and Metabolism 87 136-143. (doi:10.1210/jc.87.1.136)

Singh R, Artaza JN, Taylor WE, Gonzalez-Cadavid NF \& Bhasin S 2003 Androgens stimulate myogenic differentiation and inhibit adipogenesis in $\mathrm{C} 3 \mathrm{H}$ 10T1/2 pluripotent cells through an androgen receptor-mediated pathway. Endocrinology 144 5081-5088. (doi:10.1210/en.2003-0741)

Smith MR 2004 Changes in fat and lean body mass during androgendeprivation therapy for prostate cancer. Urology 63 742-745. (doi:10.1016/j.urology.2003.10.063) 
Smith MR, Lee H \& Nathan DM 2006 Insulin sensitivity during combined androgen blockade for prostate cancer. Journal of Clinical Endocrinology and Metabolism 91 1305-1308. (doi:10.1210/jc.2005-2507)

Spitzer M, Huang G, Basaria S, Travison TG \& Bhasin S 2013 Risks and benefits of testosterone therapy in older men. Nature Reviews. Endocrinology 9 414-424. (doi:10.1038/nrendo.2013.73)

Srinivas-Shankar U, Roberts SA, Connolly MJ, O'Connell MD, Adams JE, Oldham JA \& Wu FC 2010 Effects of testosterone on muscle strength, physical function, body composition, and quality of life in intermediate-frail and frail elderly men: a randomized, double-blind, placebo-controlled study. Journal of Clinical Endocrinology and Metabolism 95 639-650. (doi:10.1210/jc.2009-1251)

Svartberg J, Agledahl I, Figenschau Y, Sildnes T, Waterloo K \& Jorde R 2008 Testosterone treatment in elderly men with subnormal testosterone levels improves body composition and BMD in the hip. International Journal of Impotence Research 20 378-387. (doi:10.1038/ijir.2008.19)

Tajar A, Forti G, O’Neill TW, Lee DM, Silman AJ, Finn JD, Bartfai G, Boonen S, Casanueva FF, Giwercman A et al. 2010 Characteristics of secondary, primary, and compensated hypogonadism in aging men: evidence from the European Male Ageing Study. Journal of Clinical Endocrinology and Metabolism 95 1810-1818. (doi:10.1210/jc.2009-1796)

Tajar A, Huhtaniemi IT, O’Neill TW, Finn JD, Pye SR, Lee DM, Bartfai G, Boonen S, Casanueva FF, Forti G et al. 2012 Characteristics of androgen deficiency in late-onset hypogonadism: results from the European Male Aging Study (EMAS). Journal of Clinical Endocrinology and Metabolism $\mathbf{9 7}$ 1508-1516. (doi:10.1210/jc.2011-2513)

Travison TG, Araujo AB, Kupelian V, O’Donnell AB \& McKinlay JB 2007 The relative contributions of aging, health, and lifestyle factors to serum testosterone decline in men. Journal of Clinical Endocrinology and Metabolism 92 549-555. (doi:10.1210/jc.2006-1859)

Travison TG, Shackelton R, Araujo AB, Hall SA, Williams RE, Clark RV, O'Donnell AB \& McKinlay JB 2008 The natural history of symptomatic androgen deficiency in men: onset, progression, and spontaneous remission. Journal of the American Geriatrics Society 56 831-839. (doi:10.1111/j.1532-5415.2008.01679.x)

Vigen R, O’Donnell CI, Baron AE, Grunwald GK, Maddox TM, Bradley SM, Barqawi A, Woning G, Wierman ME, Plomondon ME et al. 2013 Association of testosterone therapy with mortality, myocardial infarction, and stroke in men with low testosterone levels. Journal of the American Medical Association 310 1829-1836. (doi:10.1001/jama.2013.280386)

Wallace IR, McKinley MC, Bell PM \& Hunter SJ 2013 Sex hormone binding globulin and insulin resistance. Clinical Endocrinology 78 321-329. (doi:10.1111/cen.12086)

Wang C, Nieschlag E, Swerdloff R, Behre HM, Hellstrom WJ, Gooren LJ, Kaufman JM, Legros JJ, Lunenfeld B, Morales A et al. 2009 Investigation, treatment, and monitoring of late-onset hypogonadism in males: ISA, ISSAM, EAU, EAA, and ASA recommendations. Journal of Andrology 30 1-9. (doi:10.2164/jandrol.108.006486)
Wu FC 2012 Caveat emptor: does testosterone treatment reduce mortality in men? Journal of Clinical Endocrinology and Metabolism 97 1884-1886. (doi:10.1210/jc.2012-1977)

Wu FC, Tajar A, Beynon JM, Pye SR, Silman AJ, Finn JD, O’Neill TW, Bartfai G, Casanueva FF, Forti G et al. 2010 Identification of late-onset hypogonadism in middle-aged and elderly men. New England Journal of Medicine 363 123-135. (doi:10.1056/NEJMoa0911101)

Xu XF, De Pergola G \& Bjorntorp P 1991 Testosterone increases lipolysis and the number of $\beta$-adrenoceptors in male rat adipocytes. Endocrinology 128 379-382. (doi:10.1210/endo-128-1-379)

Xu L, Freeman G, Cowling BJ \& Schooling CM 2013 Testosterone therapy and cardiovascular events among men: a systematic review and meta-analysis of placebo-controlled randomized trials. BMC Medicine 11 108. (doi:10.1186/1741-7015-11-108)

Yeap BB 2011 Osteocalcin: an endocrine link between bone and glucose metabolism. Expert Review of Endocrinology \& Metabolism 6 177-185. (doi:10.1586/eem.11.7)

Yeap BB, Alfonso H, Chubb SA, Handelsman DJ, Hankey GJ, Norman PE \& Flicker L 2012a Reference ranges and determinants of testosterone, dihydrotestosterone, and estradiol levels measured using liquid chromatography-tandem mass spectrometry in a population-based cohort of older men. Journal of Clinical Endocrinology and Metabolism 97 4030-4039. (doi:10.1210/jc.2012-2265)

Yeap BB, Araujo AB \& Wittert GA $2012 b$ Do low testosterone levels contribute to ill-health during male ageing? Critical Reviews in Clinical Laboratory Sciences 49 168-182. (doi:10.3109/10408363.2012.725461)

Yialamas MA, Dwyer AA, Hanley E, Lee H, Pitteloud N \& Hayes FJ 2007 Acute sex steroid withdrawal reduces insulin sensitivity in healthy men with idiopathic hypogonadotropic hypogonadism. Journal of Clinical Endocrinology and Metabolism 92 4254-4259. (doi:10.1210/jc. 2007-0454)

Yu IC, Lin HY, Liu NC, Sparks JD, Yeh S, Fang LY, Chen L \& Chang C 2013 Neuronal androgen receptor regulates insulin sensitivity via suppression of hypothalamic NF-кB-mediated PTP1B expression. Diabetes 62 411-423. (doi:10.2337/db12-0135)

Zitzmann M \& Nieschlag E 2007 Androgen receptor gene CAG repeat length and body mass index modulate the safety of long-term intramuscular testosterone undecanoate therapy in hypogonadal men. Journal of Clinical Endocrinology and Metabolism 92 3844-3853. (doi:10.1210/jc.2007-0620)

Zitzmann M, Faber S \& Nieschlag E 2006 Association of specific symptoms and metabolic risks with serum testosterone in older men. Journal of Clinical Endocrinology and Metabolism 91 4335-4343. (doi:10.1210/ jc.2006-0401)

Zumoff B, Miller LK \& Strain GW 2003 Reversal of the hypogonadotropic hypogonadism of obese men by administration of the aromatase inhibitor testolactone. Metabolism 52 1126-1128. (doi:10.1016/S00260495(03)00186-0)

Received in final form 6 December 2013

Accepted 13 December 2013

Accepted Preprint published online 18 December 2013 http://joe.endocrinology-journals.org DOI: 10.1530/JOE-13-0393
(C) 2014 Society for Endocrinology Printed in Great Britain
Published by Bioscientifica Ltd. 